GLOBAL WATER PATHOGEN PROJECT

PART THREE. SPECIFIC EXCRETED PATHOGENS: ENVIRONMENTAL AND EPIDEMIOLOGY ASPECTS

\title{
SCHISTOSOMA SPP.
}

\section{Jerome Boissier}

University of Perpignan

Perpignan, France

Gabriel Mouahid

University of Perpignan Via Domitia

Perpignan, France

Hélène Moné

University of Perpignan Via Domitia

Perpignan, France 


\section{Copyright:}

\section{cc) (1) (2) \\ BY SA}

This publication is available in Open Access under the Attribution-ShareAlike 3.0 IGO (CC-BY-SA 3.0 IGO) license (http://creativecommons.org/licenses/by-sa/3.0/igo). By using the content of this publication, the users accept to be bound by the terms of use of the UNESCO Open Access Repository (http://www.unesco.org/openaccess/terms-use-ccbysa-en).

\section{Disclaimer:}

The designations employed and the presentation of material throughout this publication do not imply the expression of any opinion whatsoever on the part of UNESCO concerning the legal status of any country, territory, city or area or of its authorities, or concerning the delimitation of its frontiers or boundaries. The ideas and opinions expressed in this publication are those of the authors; they are not necessarily those of UNESCO and do not commit the Organization.

\section{Citation:}

Boissier, J., Mouahid, G. and Moné, H. (2019). Schistosoma spp. In: J.B. Rose and B. Jiménez-Cisneros (eds), Water and Sanitation for the 21st Century: Health and Microbiological Aspects of Excreta and Wastewater Management (Global Water Pathogen Project). (L. Robertson (eds), Part 3: Specific Excreted Pathogens: Environmental and Epidemiology Aspects - Section 4: Helminths), Michigan State University, E. Lansing, MI, UNESCO. https://doi.org/10.14321/waterpathogens.45

Acknowledgements: K.R.L. Young, Project Design editor; WebsiteDesign: Agroknow (http://www.agroknow.com)

Last published: March 29, 2019 


\section{Summary}

Schistosomiasis (or bilharzia) is one of the most prevalent waterborne parasitic diseases. The epidemiological statistics associated with schistosomiasis are impressive: 800 million people are at risk in 78 countries, mostly concentrated in sub-Saharan Africa; 230 million are infected and the disease is responsible for between 1.7 and 4.5 million disability adjusted life years (DALYs). The most exposed people are children or young adults.

The etiological agent of schistosomiasis is a helminth from Schistosoma genus living in the blood vessels of the body. Six species are known to be pathogenic for humans. Five species live in the mesenteric vein system and cause intestinal schistosomiasis (Schistosoma mansoni, $S$. intercalatum, S. guineensis, S. mekongi, S. japonicum) while $S$. haematobium lives in the venous plexus around the bladder and causes urinary schistosomiasis. Humans excrete the pathogen in faeces or urine, depending on species and location. Female worms produce numerous eggs (200-3,000 per day), thus resulting in the potential for considerable environmental contamination. In contaminated water, the parasite species uses a specific freshwater snail as an intermediate host for completion of the lifecycle. Transmission to humans occurs when the parasite penetrates the skin on the definitive host, including humans. The pathology is mainly of schistosomiasis is largely caused by the accumulation of the parasite eggs that are not excreted. Many eggs become trapped in different organs, mainly in the intestines and the liver for intestinal schistosomiasis or in the urogenital system for urinary schistosomiasis. Few patients develop acute schistosomiasis and most symptoms appear several months after parasite penetration (chronic schistosomiasis). Intestinal schistosomiasis causes hepatosplenomegaly, fever, abdominal pain, and bloody diarrhea. Urinary schistosomiasis causes blood in the urine and painful urinations. Schistosomiasis also impacts child development and school performance.

The diagnostic standard for schistosomiasis requires urine (Schistosoma haematobium) or faeces (Schistosoma mansoni, S. intercalatum, S. guineensis, S. mekongi, S. japonicum) examination. The egg shape gives indication on the species concerned. Serological tests like Elisa or Western Blot, and DNA detection in the faeces, urine or serum are also available. Treatment mainly relies on the use of a single antihelminthic drug: praziquantel (no vaccine is available). Control programmes also include molluscicide treatment (to remove the intermediate host), improved environmental sanitation, and health education.

\subsection{Epidemiology of the Disease and Pathogen(s)}

\subsection{Global Burden of Disease}

\subsubsection{Global distribution}

The geographical distribution of schistosomiasis is presented in Figure 1 according to the status of the different endemic countries (WHO, 2013): the countries requiring preventive chemotherapy; the countries requiring updating for planning and implementation purposes, the countries requiring evaluation in order to verify if interruption of transmission has been achieved. We added to this distribution the newly emergent region for schistosomiasis, Corsica, France (Holtfreter et al., 2014; Berry et al., 2014).

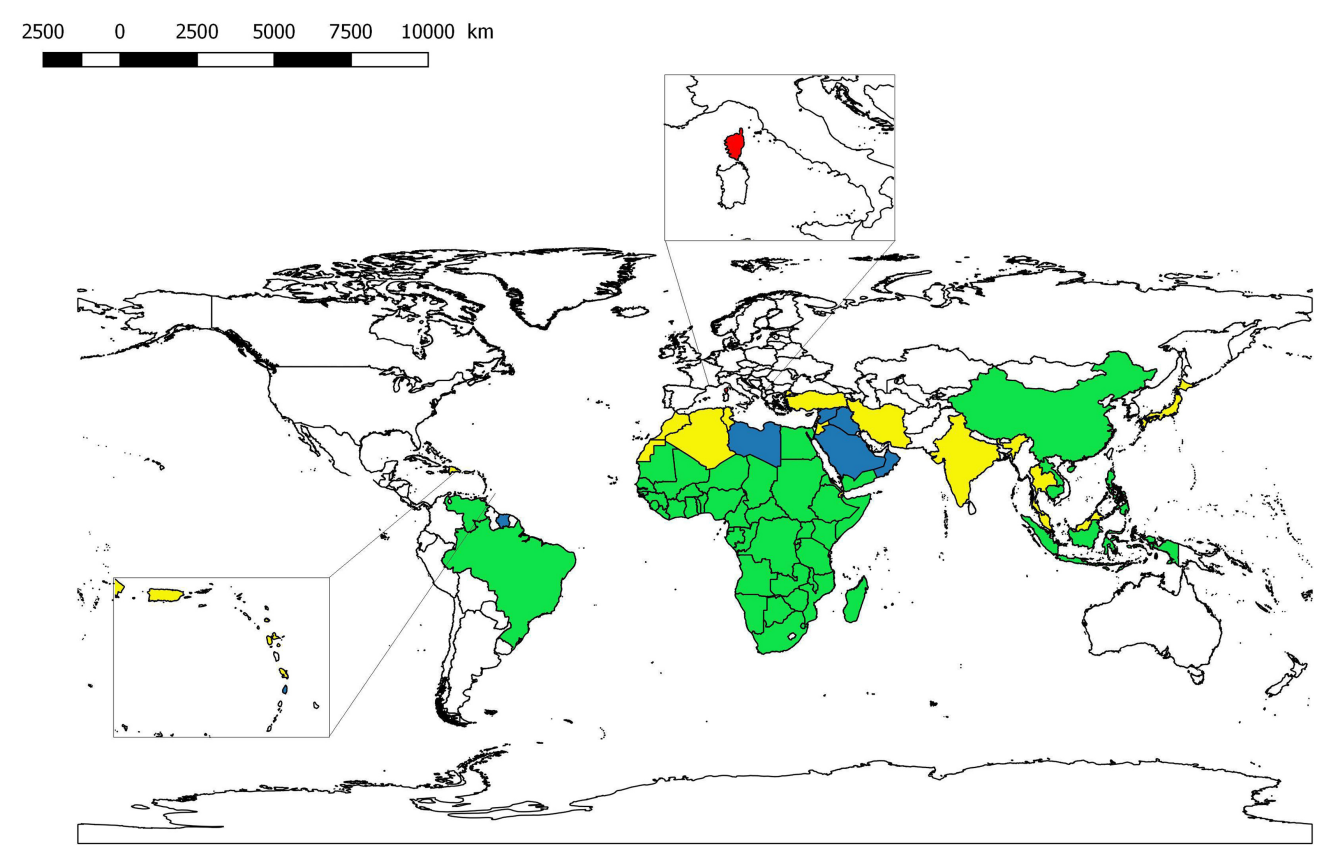

Figure 1. Endemic countries for schistosomiasis (WHO, 2013): those requiring preventive chemotherapy (green); those requiring updating for planning and implementation purposes (blue), those requiring evaluation in order to verify if interruption of transmission has been achieved (yellow). We added to this distribution the newly emergent region for schistosomiasis, Corsica, France (red) (Berry et al., 2014; Holtfreter et al., 2014). The scale is for the main map and not for the two zoomed country zones. 
The distribution of each schistosome species is limited by the distribution of its snail intermediate host. Schistosoma japonicum uses Oncomelania snails as intermediate hosts (Figure 2). This parasite is present in China but a huge effort has been done to control the disease (Cao et al., 2016; Yang et al., 2016), in Philippines and in Indonesia (WHO, 2013). Schistosoma mekongi uses Neotricula snails as intermediate hosts (Figure 2). This parasite is restricted to the Mekong Delta in Laos and Cambodia. Schistosoma mansoni is transmitted by the genus Biomphalaria. In South American and Caribbean countries $S$. mansoni is transmitted mainly by Biomphalaria glabrata snails (Figures 2). Within the Caribbean Islands of Antigua and Barbuda, Dominican Republic, Guadeloupe, Martinique, Montserrat and Puerto-Rico schistosomiasis transmission seems to be interrupted (Zoni et al., 2016). However, we must remain cautious because if we take the case of the Guadeloupe, the last case of human infection was reported in 2000 in an hospitalized patient (Nicolas et al., 2006) and no data is available for this area since 2004. The parasite remains present in Brazil, Venezuela, Suriname and Santa-Lucia
(Zoni et al., 2016). The principal transmission of S. mansoni occurs in Africa and Middle East where the parasite uses Biomphalaria pfeifferi (Figure 2), Biomphalaria tenagophila, Biomphalaria sudanica and Biomphalaria straminea as intermediate hosts. S. mansoni is found in 38 African countries as well as 7 Eastern Mediterranean countries (Chitsulo et al., 2000; Rollinson et al., 2013). Schistosoma haematobium uses snails of the genus Bulinus (Figure 3) as intermediate hosts (Brown, 1994). S. haematobium is found in 37 countries from Africa and 15 from Eastern Mediterranean countries (Chitsulo et al., 2000; Rollinson et al., 2013). Schistosoma mansoni and S. haematobium are co-endemic in 35 countries. Schistosoma guineensis and S. intercalatum have a restricted geographical range. S. guineensis occurs in the Gulf of Guinea including Cameroon, Equatorial Guinea, Gabon, and Sao Tomé \& Principe and S. intercalatum is strictly limited to the Democratic Republic of the Congo (Zaire) (Pagès et al., 2003). The two species use B. forskalii and B. africanus, respectively as snail intermediate hosts.
(A)

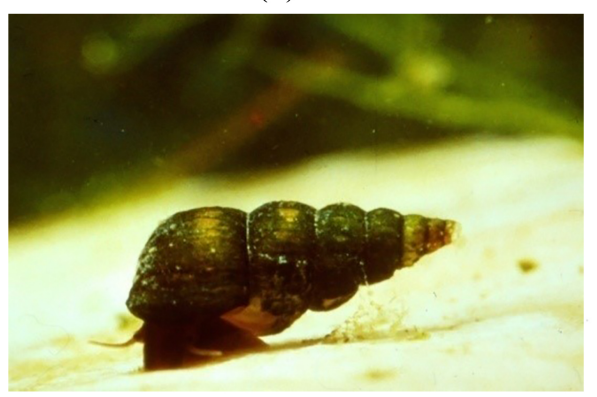

(D)

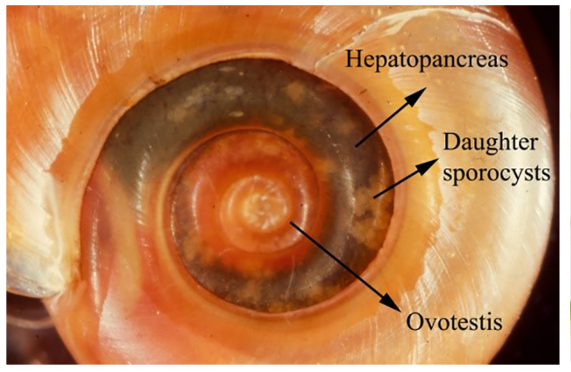

(B)

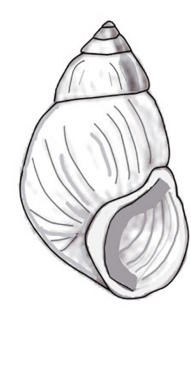

(C)

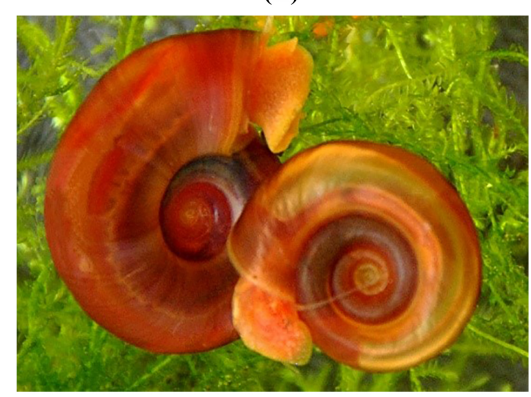

(E)

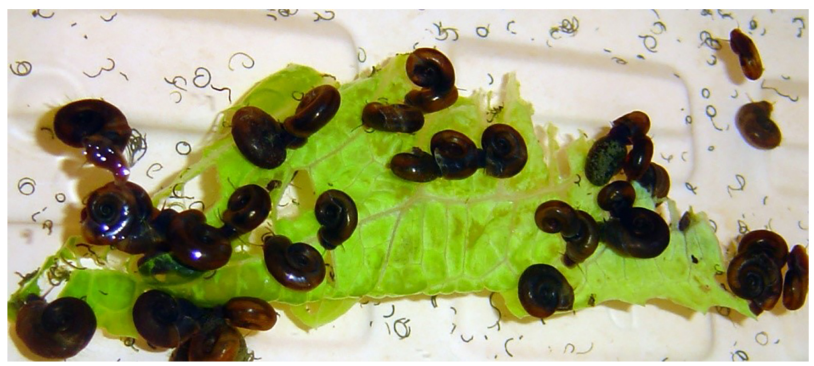

Figure 2. A. Oncomelania hupensis (Gastropoda, Pomatiopsidae), snail intermediate host of Schistosoma japonicum. B. Apertural view of a shell of Neotricula aperta (Gastropoda, Pomatiopsidae), snail intermediate host of Schistosoma mekongi. C. Biomphalaria glabrata albino strain (Gastropoda, Planorbidae), snail intermediate host of Schistosoma mansoni. D. B. glabrata albino strain infected by S. mansoni, the daughter sporocysts are easily visible at the level of hepatopancreas and ovotestis. E. Biomphalaria pfeifferi (Gastropoda, Planorbidae), snail intermediate host of Schistosoma mansoni. 


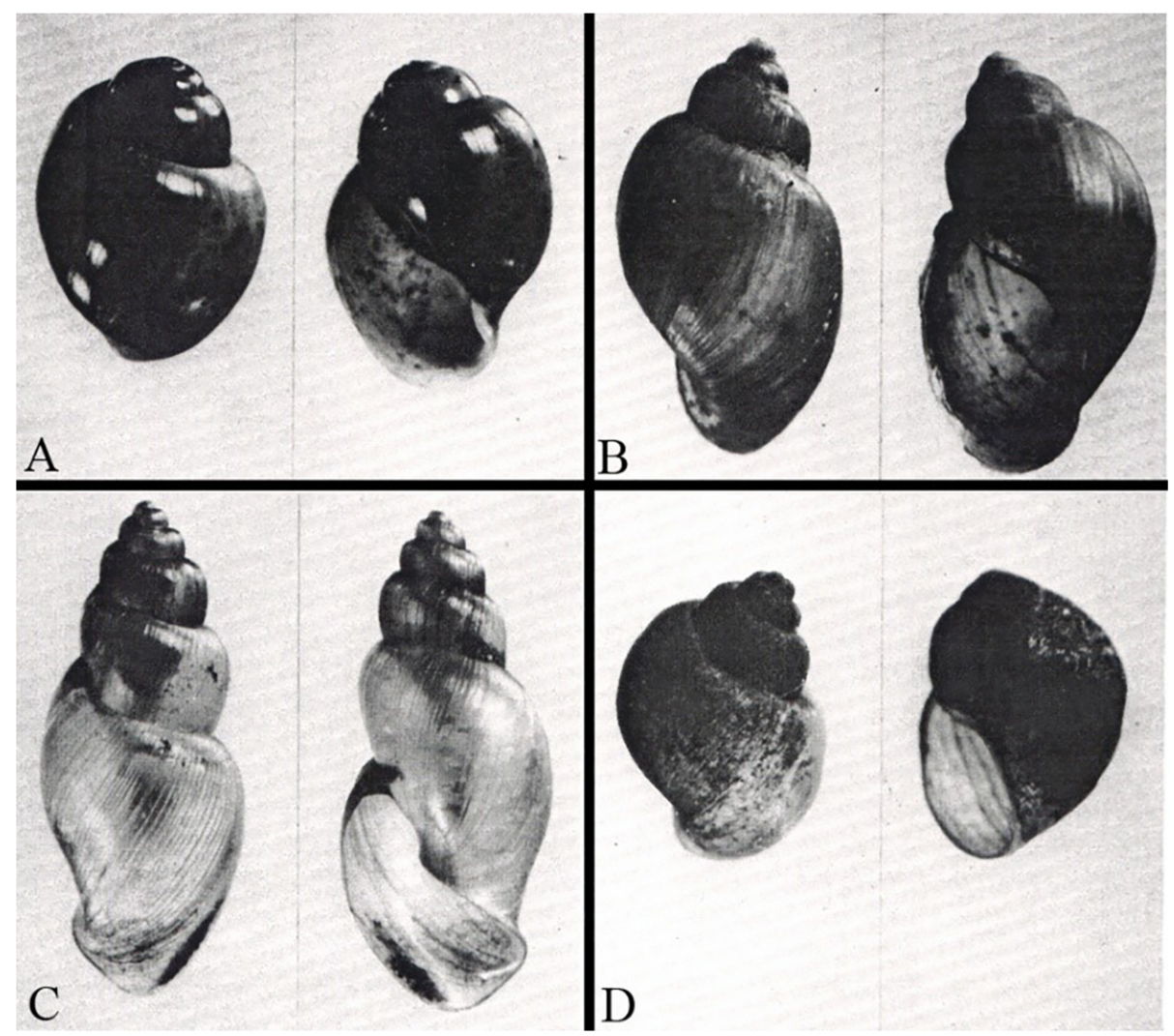

Figure 3. Shells of Bulinus snails, the intermediate hosts of Schistosoma species belonging to the S. haematobium group (in Africa, Madagascar, Middle East and Europe). Taxonomically, the genus Bulinus includes 4 groups (Mandahl-Barth, 1957; Brown, 1994): B. africanus group (represented by B. globosus in A), B. truncatus/tropicus group (represented by B. truncatus in B), B. forskalii group (represented by B. crystallinus in C) and B. reticulatus group (represented by $B$. wrighti in D).

An emergence of Schistosomiasis haematobium occurs in France on the island of Corsica (Berry et al., 2014; Holtfreter et al., 2014; Boissier et al., 2015). The parasite is a hybrid between human (S. haematobium) and livestock (S. bovis) parasites (Moné et al., 2015). Its origin is Senegal (Boissier et al., 2016), and it uses Bulinus truncatus as intermediate host. Schistosomes are known to hybridize and natural hybrids are frequently identified in human hosts (summarized in Table 1). Natural hybridizations are known (i) between schistosome species infecting humans (S. haematobium, S. guineensis or S. mansoni) (ii) between schistosome species infecting animals $(S$. bovis and $S$. curassoni) (iii) and between schistosome species infecting human and schistosome species infecting animals (rodents, S. rodhaini or ruminants, $S$. bovis and S. mattheei). These last hybrid parasites are particularly worrying because they raise the possibility of zoonotic transmission.

Table 1. Natural hybrid schistosomes

\begin{tabular}{|c|c|c|c|}
\hline Area & $\begin{array}{c}\text { Species } \\
\text { Hybridized }\end{array}$ & $\begin{array}{c}\text { Species } \\
\text { Hybridized }\end{array}$ & Reference \\
\hline \multicolumn{4}{|c|}{ Hybridization Between Human Schistosomes } \\
\hline $\begin{array}{l}\text { Benin, Cameroon and } \\
\text { Gabon }\end{array}$ & S. haematobium & S. guineensisa & $\begin{array}{c}\text { Wright et al., 1974; Southgate et al., } \\
\text { 1976; Burchard and Kern, 1985; } \\
\text { Webster et al., 2005; Moné et al., } \\
2014\end{array}$ \\
\hline Senegal & S. haematobium & S. mansoni & Huyse et al., 2013 \\
\hline \multicolumn{4}{|c|}{ Hybridization between animal schistosomes } \\
\hline
\end{tabular}




\begin{tabular}{lccc}
\hline \multicolumn{1}{c}{ Area } & $\begin{array}{c}\text { Species } \\
\text { Hybridized }\end{array}$ & $\begin{array}{c}\text { Species } \\
\text { Hybridized }\end{array}$ & Reference \\
\hline Hybridization between human schistosomes and animal schistosomes \\
Benin, Niger and Senegal & S. haematobium & S. bovis & $\begin{array}{c}\text { Brémond et al., 1993; Huyse et al., } \\
\text { 2009; Webster et al., 2013; Moné et } \\
\text { al., 2015 }\end{array}$ \\
Kenya, Tanzania & S. mansoni & Morgan et al., 2003; Steinauer et al., \\
Senegal & S. haematobium & S. rodhaini & Webster et al., 2013 \\
South Africa & S. haematobium & S. curassoni & Pitchford, 1961
\end{tabular}

${ }^{a} S$. intercalatum only exists in The Democratic Republic of the Congo (Pagès et al., 2003); before this date, some authors used this species name for strains from Cameroon and Gabon; in this table, we used the species name $S$. guineensis

\subsubsection{Symptomatology}

An urticarial rash (maculopapular lesions) may be present where the cercariae penetrate the skin (discrete erythematous raised lesions that vary in size from 1-3 cm); migrants or tourists infected for the first time may develop a skin reaction within a few hours, although a rash may appear up to a week later (Gray et al., 2011).

Schistosomiasis progresses in two successive phases: acute and chronic. The acute phase is common to all schistosomiasis infections and is characterized by Katayama syndrome which appears 14 to 84 days after initial infection and corresponds to allergic reaction against developing schistosomula. Symptoms associated are nocturnal fever, cough, myalgia, headache, and abdominal tenderness (Ross et al., 2007).

The intensity of the chronic phase is strongly but not exclusively related to the intensity of infection (Dunne and Pearce, 1999; Gryseels et al., 2006; Colley et al., 2014). The localization of the pathology depends on the species considered but the main lesion is always the same: granuloma formation around schistosome eggs. Long term infection (several months or years) leads to fibrosis of organs containing trapped eggs. Symptoms depend on the species implicated. Uro-genital schistosomiasis caused by $S$. haematobium provokes haematuria (microscopic or macroscopic), burning micturition and renal dysfunction (Colley and Secor, 2014). Carcinoma is also associated with S. haematobium infection (Schwartz, 1981). Genital schistosomiasis strongly affects female reproductive health causing incontinency, infertility and increase risk of abortion (Kjetland et al., 2012). Uro-genital schistosomiasis also affects male genital function including sterility cases or prostate carcinoma (Figueiredo et al., 2015). For hepatointestinal schistosomiasis ( $S$. mansoni or $S$. japonicum), the symptoms of chronic phase are weakness, fatigue, irregular bowel movement, abdominal pain, diarrhea and blood in stools. Hepatosplenic lesions with fibrosis in the portal tracts of the liver are the most serious complication. The occurrence of hepatic fibrosis depends on the species concerned and the number of eggs shed daily by a female. A S. japonicum female releases up to 3,000 eggs every day and hepatic fibrosis can occur within two years post infection. A S. mansoni female releases up to 300 eggs daily and hepatic fibrosis can occur within 5 to 10 years after infection.

\subsubsection{Morbidity and mortality}

Schistosomiasis ranks second after malaria for parasitic diseases in terms of mortality and morbidity. Globally it is estimated that 800 million people are at risk of acquiring infection and 252 million are infected (Lozano et al., 2012; Murray et al., 2012; Vos et al., 2012; Hotez et al., 2014). However, these figures may be underestimated considering that current diagnostic methods are not always sensitive enough to detect light infections. Extreme controversies exist in the calculation of Disability-Adjusted Life Year (DALYs) for Schistosomiasis with values ranging from 1.7 to 57 million (Hotez et al., 2014). The Global Burden Disease (GBD) published in 2010 an estimate of 3.31 million DALYs lost due to Schistosoma infections (King, 2010; Murray et al., 2012; Hotez et al., 2014). For Schistosomiasis, 10\% of the DALYs are Years of Life Lost (YLLs) due to premature mortality and 90\% are Years Lived with Disability (YLDs) (Hotez et al., 2014). The rank of schistosomiasis DALYs among the neglected tropical diseases jumped from the rank of 7 (on 17 referenced diseases) to the rank of 3 between 1990 and 2010 (Hotez et al., 2014). Schistosomiasis has also negative effects on performance status and quality of life for chronically infected people. Schistosomiasis infection is associated with under-nutrition, lost years of schooling, growth stunting, cognitive impairment, exercise intolerance or general fatigue (King et al., 2005). 


\subsection{Taxonomic Classification of the Agent(s)}

\subsubsection{Taxonomy}

Schistosomiasis or Bilharziasis is caused by a worm parasite of the genus Schistosoma. Schistosomes are digenetic trematodes belonging to the family of Schistosomatidae. All the 23 known Schistosoma species are parasites of mammals with 6 of these having high medical importance. Schistosomes are classically spliced into 4 clades (referred as S. mansoni - S. japonicum - S. indicum - $S$. haematobium clades) according to the egg morphology, the intermediate host used and their geographic distribution (Rollinson and Simpson, 1987). Recently it has been proposed to split schistosomes into 6 clades according to phylogenetic relationships and geographical distribution (Lawton et al., 2011): the basal $S$. japonicum clade is present in Central and South-East Asia (including $S$. japonicum and $S$. mekongi), the $S$. hippopotami clade is present in Africa, the Proto-S. mansoni clade is present in Central Asia, Middle East and Eastern Europe, the S. mansoni clade (including S. mansoni) is present in Africa, South America and Middle East, the $S$. indicum clade is present in India and in Asia and the $S$. haematobium clade is present in Africa and Middle East (including $S$. intercalatum, $S$. haematobium and $S$. guineensis).

\subsubsection{Physical description (morphology)}

Physical description depends on the life cycle stage considered. The mammal infecting stage is a worm. Among the thousands species of trematodes, schistosomes have the particularity to have separate sexes. The muscular male is white and around $\sim 1 \mathrm{~cm}$ in size. The female is black, longer $(\sim 1.5 \mathrm{~cm})$ but thinner than the male. The female lives in a ventral groove of the male called gynaecophoral canal. The black color of the female is due to the disposal product of hemoglobin degradation (called hemozoin) resulting from red blood cell ingestion (Portela et al., 2012). This product is similar to the disposal product of malaria called malarial pigment.

The free larval stage infecting the mollusc (miracidium) measures $100 \times 50 \mu \mathrm{m}$ and is covered by cilia. Miracidia can be confused with a ciliated protozoa but miracidium is a complex multicellular organism (Figure 4). The free larval stage infecting mammals (cercaria) is divided into two parts: tail and body. The tail (150-250 x 25-30 $\mu \mathrm{m})$ possesses a furca and is dedicated to the swimming behavior and does not penetrate into the host (Figure 5). The body $(150-200 \quad \mathrm{x} \quad 40-70 \mu \mathrm{m})$ will become the schistosomulum then the adult form in the mammal host. The main characteristic of schistosome eggs (used in diagnosis) are the absence of operculum, the presence of fully developed miracidia and the presence of spine: terminal (S. haematobium clade), subterminal (S. japonicum clade) or lateral (S. mansoni clade).

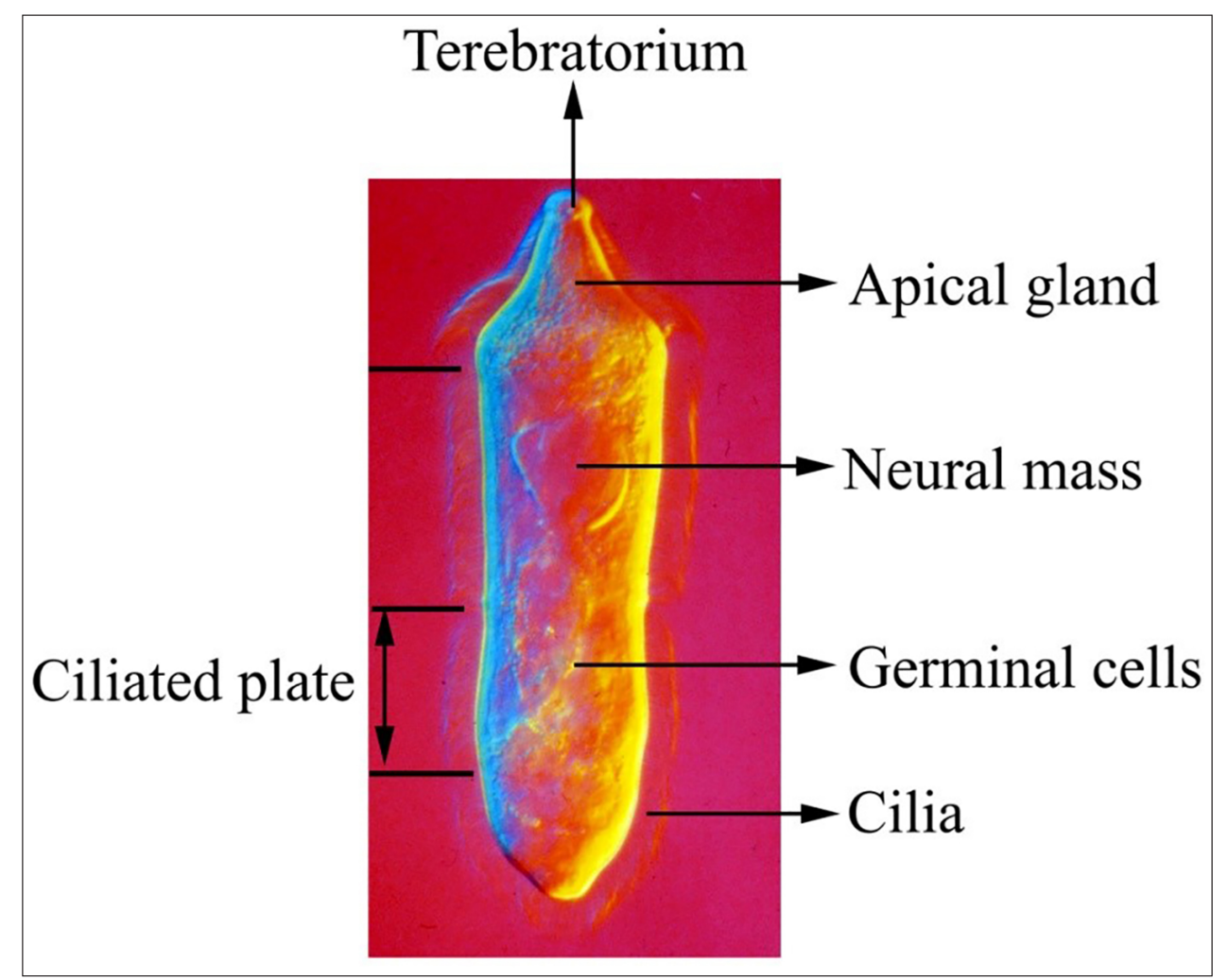

Figure 4. Miracidium of Schistosoma mansoni ( $\sim 150 \mu \mathrm{m}$ long) observed under a phase contrast microscope. It is a free swimming larva thanks to its epidermal ciliated plates. The terebratorium (apical papilla) facilitates attachment to the snail host tegument. 


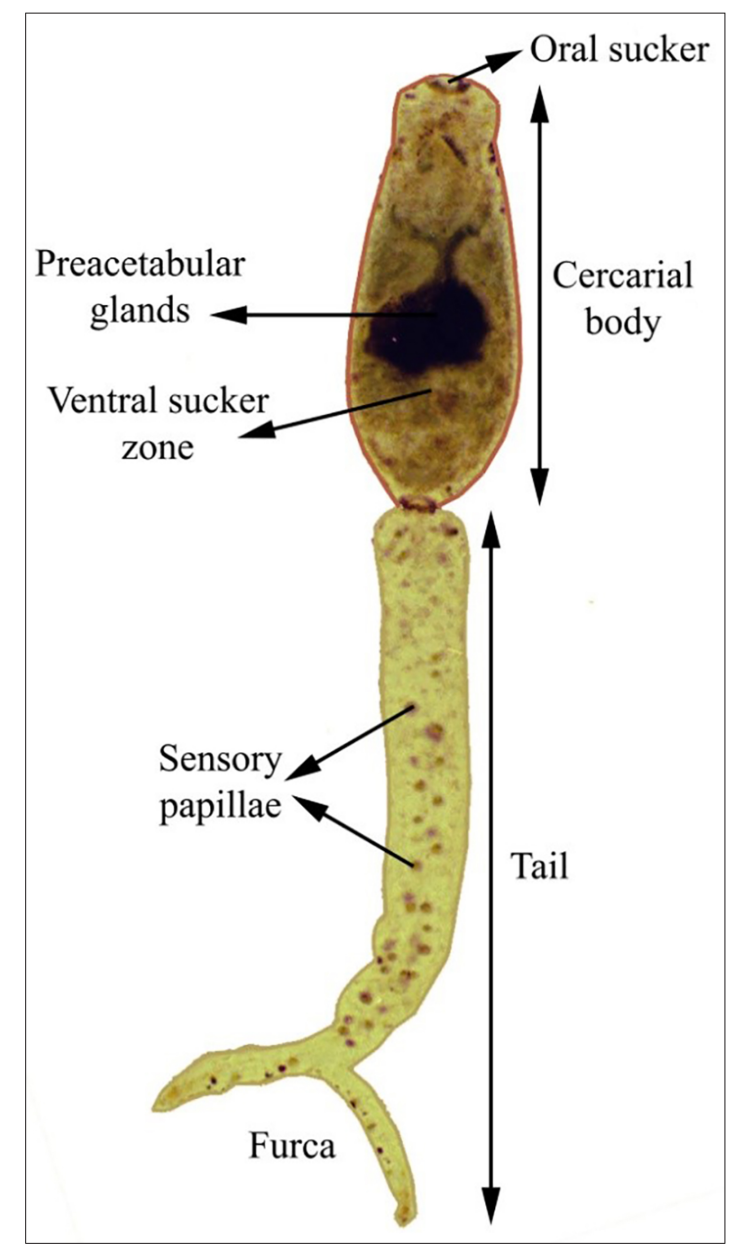

Figure 5. Dorsal view of a Schistosoma mansoni cercaria observed under the light microscope after a fixation in silver nitrate $(\sim 330 \mu \mathrm{m}$ long). It is a swimming larva thanks to its bifurcated tail. The oral sucker and the ventral sucker (known as acetabulum) facilitate attachment to the tegument of the definitive host. Pre- and post-acetabular glands facilitate host penetration thanks to their proteases. The tail is shed upon penetration. 


\subsection{Transmission}

\subsubsection{Lifecycle, routes of transmission}

Human schistosomes have a complex lifecycle including two obligatory hosts (Figure 6): a vertebrate definitive host, the human (or other mammalians as reservoir hosts), where the adult schistosomes pair and reproduce and a gastropod snail intermediate host where the larvae, called sporocysts, multiply asexually. Transmission from the vertebrate host to the freshwater snail vector is ensured by the miracidium larva. Transmission from the snail host to the vertebrate host is ensured by the cercaria larva during exposure to water with active penetration.

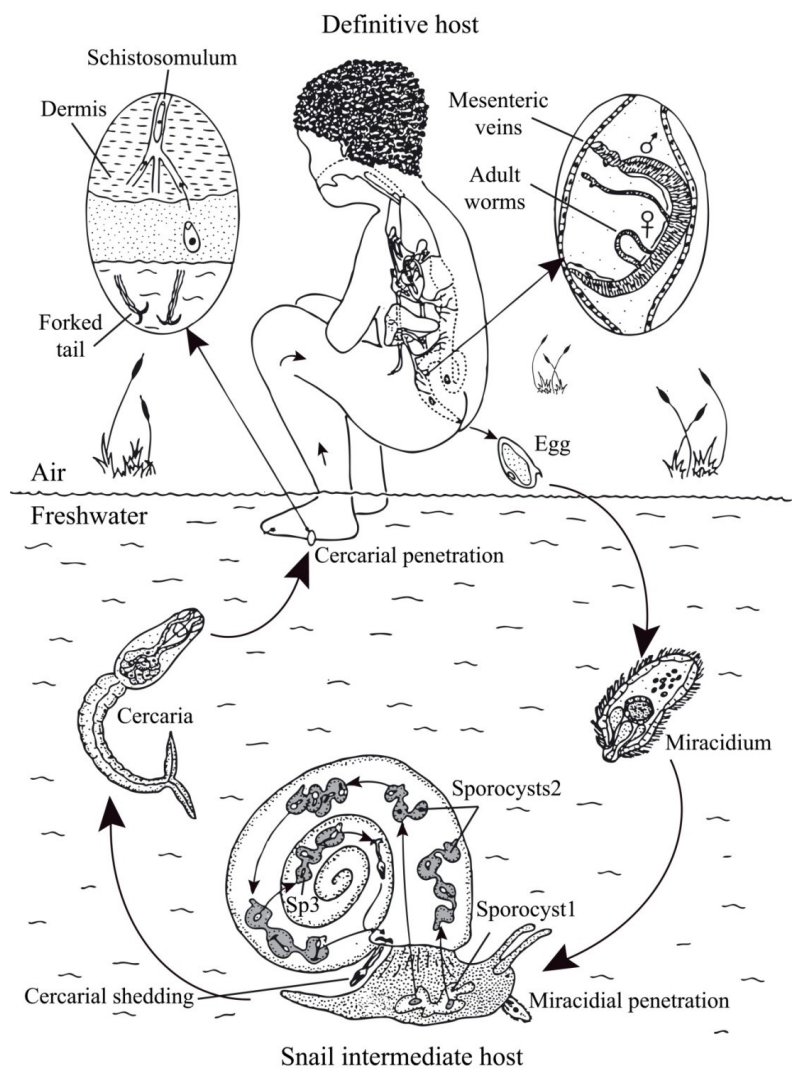

Figure 6. Life cycle of Schistosoma mansoni. When the stool of an infected human reaches freshwater, each egg releases a free swimming ciliated larva called miracidium (there is no incubation period). This larva has just a few hours to find and actively penetrate a freshwater snail of the genus Biomphalaria. Inside the headfoot region, the miracidium develops and becomes mother sporocyst (or sporocyst 1) in which many daughter-sporocysts (or sporocyst 2) develop by asexual multiplication.These larval stages leave the headfoot region to colonize different target organs as the hepatopancreas and the ovotestis of the snail host. The sporocysts $\geq 2$ generate new swimming larval stages, the cercariae formed by a head and a forked tail. The development of a single miracidium may result in thousands of cercariae, each one able to penetrate human skin actively. After penetration, the cercaria becomes schistosomulum and undertakes a complex migration through the body in the bloodstream that ends ultimately to the liver where males and females mate, become sexually mature then migrate to the egg-laying site, mesenteric veins for S. mansoni. Egg must pass through the vessel and the intestine walls to be discharged outside with the stool.

The adult schistosomes are dioecious; this gonochorism is associated with morphological, ecological, behavioural and molecular differences between the male and the female schistosomes all along their life cycle (Moné and Boissier, 2004). They live in the mesenteric vein vessels irrigating the intestine (all human schistosomes, except S. haematobium) or the urogenital vein plexus region (S. haematobium). The eggs are laid in the blood (hundreds or even thousands per day). The mechanisms by which eggs move through the vessel walls and the tissues to reach the lumen are not well understood. It is likely that numerous interacting factors are involved as the spine of the egg, blood pressure, peristalsis and proteolytic enzymes secreted by miracidia (Jourdane and Théron, 1987). The egg upon reaching freshwater, the miracidium hatches and has few hours to find and actively penetrate the appropriate snail host. In case of good host parasite compatibility, the miracidium becomes a mother sporocyst (or sporocyst 1; Figure 7A) producing daughter sporocysts (or sporocysts 2; Figure 7B). 
(a)

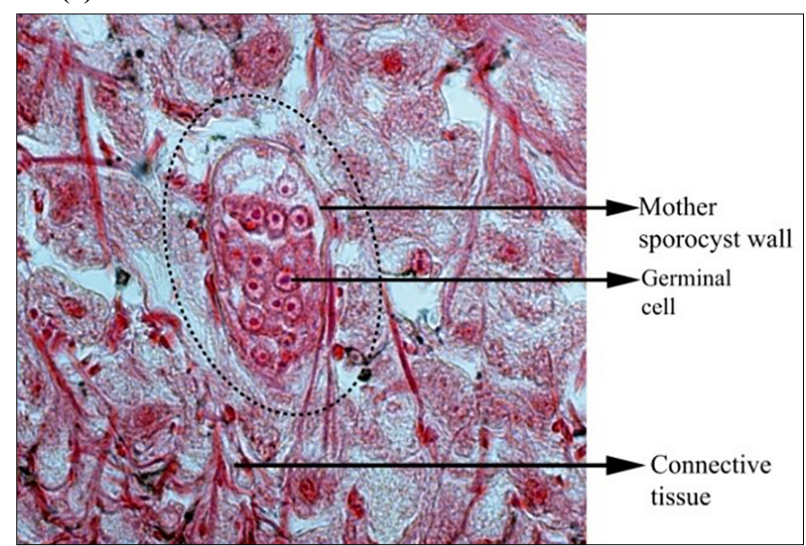

(b)

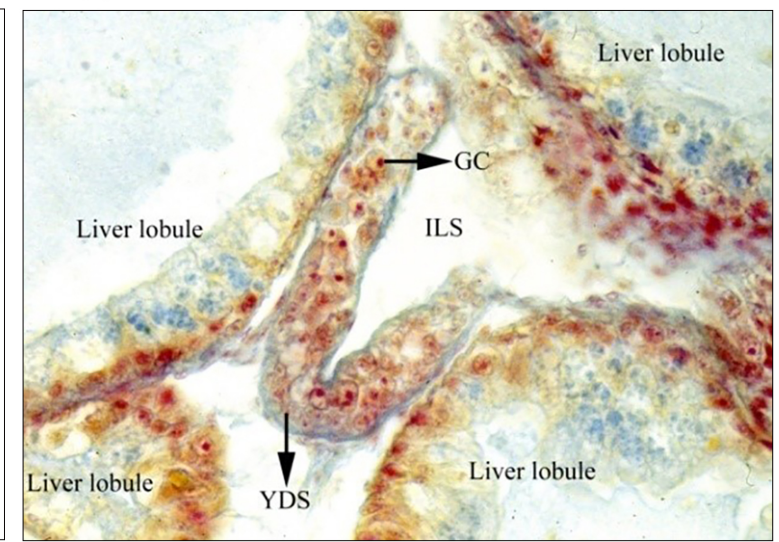

Figure 7. The S. mansoni sporocysts. (a) Mother sporocyst (dashed ellipse) in the foot region of the intermediate host Biomphalaria. Germinal cells will develop into daughter sporocysts; (b) Young worm-like daughter sporocyst in the hepatopancreas of the intermediate host Biomphalaria. GC: germinal cell; ILS: inter lobular space; YDS: young daughter sporocyst.

The daughter sporocysts live preferentially in the hepatopancreas and ovotestis of the snail host; they undergo at least two multiplication generations and give rise to cercariae that are freed from the snail body into the water and chemotax to the human host skin. The cercariae then burrow through the skin and enter the bloodstream.

\subsubsection{Intermediate hosts, reservoirs}

The snail intermediate hosts belong to different genera depending on the species of schistosome: Biomphalaria for Schistosoma mansoni, Bulinus for S. haematobium, S. intercalatum and $S$. guineensis, Oncomelania for $S$. japonicum and Neotricula for $S$. mekongi.

Humans are the vertebrate definitive hosts but other vertebrates may be found naturally infected by a species of human schistosomes and need to be considered as potential reservoirs for these diseases. Tables 2 to 4 show the 113 species that have been found naturally infected with human schistosomes. They belong to 9 orders: primates (16 species), lagomorpha (3 species), rodentia (58 species), carnivora (13 species), cetartiodactyla (11 species), perissodactyla (2 species), insectivora (6 species), xenarthra (1 species) and didelphimorphia (3 species). In summary, $S$. mansoni and $S$. japonicum are the two species that were found in a maximum of these orders-species (7-58 and 8-56 for $S$. mansoni and $S$. japonicum, respectively); these results are surprising because $S$. japonicum, which is known to have the broadest spectrum of definitive hosts, displays approximately the same numbers of orders and species compared to $S$. mansoni. We should bear in mind that efforts to analyze these natural hosts in the field may be different for the different species of schistosomes. $S$. haematobium was found in 3 orders and in 15 species, which is quite a high number considering that this schistosome has been historically characterized as being highly specific to the human host. A plausible explanation for this is the ability of $S$. haematobium to hybridize with $S$. bovis or $S$. currassoni giving rise to introgressed strains of S. haematobium (Moné et al., 2015; Boissier et al., 2016). The increase in the definitive host range can be interpreted as the result of hybrid vigor after hybridization of $S$. haematobium with species such as $S$. bovis which has a wide geographical distribution, as well as wide intermediate and definitive hosts ranges (Moné et al., 2000). Although no definitive natural host was found to be infected with $S$. guineensis, experimental infections were possible in both the cetartiodactyla Ovis aries (Frandsen et al., 1978) and the rodentia Mastomys huberti and Arvicanthis niloticus (Imbert-Establet et al., 1997). The same lack of investigation can be applied for $S$. mekongi (only two natural hosts found from two orders) and $S$. intercalatum (only one natural host found). The last three species have a limited geographical distribution: gulf of lower Guinea for $S$. guineensis, lower Mekong basin for $S$. mekongi and Democratic Republic of the Congo for $S$. intercalatum. 
Table 2. Mammalian definitive hosts (other than human) found naturally infected by human schistosome $S$. mansoni

Hosts

Primates

Lagomorpha

(Hares, rabbits and picas)

Rodentia

(Rodents)

\section{Carnivora}

(meat-eating placental mammals

Cetartiodactyla

(ungulates, such as cows and camels)

Perissodactyla (odd-toed ungulates such as zebras)

Insectivora

(obsolete as a taxonomic order, referred to as insect eaters such as moles)

Xenarthra

(placental mammals such as anteaters, tree sloths, and armadillos)

Didelphimorphia

(opposums)

\section{Species}

Cercopithecus aethiops ${ }^{a}$, C. mitis $^{b}$, C. pygerethrus ${ }^{c}$, Erythrocebus patas ${ }^{a}$,

Pan troglodytes ${ }^{a, c}$, Papio Anubis ${ }^{a, c}$, P. cynocephalus ${ }^{e}$, P. dogera ${ }^{b}$, P. hamadryas ${ }^{f, g}, P$. papio $^{a, c}$, P. ursinus $^{a, c}$, Saimiri $s p p^{a}$

None

Akodon arviculoides ${ }^{h, i}$, Arvicanthis niloticus ${ }^{a, c, k, l, m, n, o}$, Bolomys Lasiurus ${ }^{a, i}$, Calomys expulsus ${ }^{i}$, Cavia aperea $^{a, I, p}$, Damysmys $^{b}$, Dasymys incomtus ${ }^{a, c}$,

Gerbillus pyramidum $^{a, c, q}$, Holochilus brasiliensis ${ }^{a, i, p}$,

$H$. sciureus ${ }^{a, i}$, Lemniscomys griseld $a^{c, r}$, L. rosalia $^{a}$,

Lophuromys flavopunctatus $^{a, c}$, Mastomys huberti ${ }^{\text {n,s }}$, M. natalensis ${ }^{a, r}$, Mastomys $s p^{t}$, Nectomys squamipes $^{a, h, I, p, u, v}$, Oenomys hypoxanthus ${ }^{a, c}$,

Oryzomys laticeps ${ }^{i}$, O. nigripes ${ }^{i, p, w}$, O. subflavus ${ }^{a, i}, O$. utiaritensisa, $i$, Otomys angioniensis ${ }^{a, c}$

O. tugelensis ${ }^{r}$, Otomys $s p^{t}$, Oxymycterus angularis ${ }^{a, i}$,

O. hispidus ${ }^{i}$, Pelomys fallax ${ }^{a, c}$, Praomys natalensis ${ }^{c}$, Proechimys albispinus $^{i}, R$. norvegicus ${ }^{a, I, x}, R$. rattus $^{a, c, I, o, x, y, z}$, Tatera robusta ${ }^{b}$, Zygodontomys brachyurus $^{p}, Z$. brevicauda ${ }^{a}$

Canis familiaris $^{a, c, m}$, Procyon carnivorus ${ }^{a}$

${\text { Ovis } \text { aries }^{a, c}, \text { Kobus ellipsiprymnus }}^{a, c}$, Bos taurus ${ }^{a, m}$

None

C. lunaa,,$C$. oliviera ${ }^{a, c, s}$

Myrmecophaga tridactyl $a^{a}$

Didelphis albiventris ${ }^{a}$, D. aurita ${ }^{a, i}$, Lutreolina crassicaudata $^{i}$

${ }^{\mathrm{a}}$ Rollinson and Southgate, 1987; ${ }^{\mathrm{b}}$ Ouma and Fenwick, 1991; ${ }^{\mathrm{c} P i t c h f o r d, ~ 1977 ; ~}{ }^{\mathrm{d}}$ Chen, 1993; ${ }^{\mathrm{e}}$ Muller-Graf et al., 1997; ${ }_{\mathrm{f}}^{\mathrm{f}}$ Ghandour et al., 1986; ${ }^{\mathrm{G}} \mathrm{Zahed}$ et al., 1996; ${ }^{\mathrm{h}} \mathrm{Silva}$ et al., 1992; ${ }^{\mathrm{i}} \mathrm{Rey,} \mathrm{1993;}{ }^{\mathrm{k}} \mathrm{Arafa}$ and Massoud, 1990; ${ }^{\mathrm{l}} \mathrm{Mansour}, 1973$; ${ }^{\mathrm{m}}$ Karoum and Amin, 1985; ${ }^{\mathrm{n}}$ Duplantier and Sene, 2000; ${ }^{\circ}$ Mansour, 1978; ${ }^{\mathrm{p}}$ Dias et al., 1978; ${ }^{\mathrm{q}} \mathrm{Kuntz}$, 1952; ${ }^{\mathrm{r}} \mathrm{Pitchford}$ and Visser, 1962; ' Kuntz, 1958; ${ }^{\mathrm{t}}$ Pitchford, 1959; " $\mathrm{Gentile} \mathrm{et} \mathrm{al.,} \mathrm{2006;} \mathrm{'D'Andrea} \mathrm{et} \mathrm{al.,} \mathrm{2000;}{ }^{\mathrm{w}}$ Barbosa, 1972; ${ }^{\mathrm{x}} \mathrm{Günther}$, 1979; ${ }^{\mathrm{y}}$ Imbert-Establet, 1982; ${ }^{\mathrm{z}}$ Mouahid et al., 2012

NOTE: S. intercalatum found only in rodenta: Hybomys univitatus (Rollinson and Southgate, 1987); S. mekongi found only in Carnivora: Canis familiaris (Ouma and Fenwick, 1991; Rollinson and Southgate, 1987) and Cetartiodactyla: Sus scrofa (Rollinson and Southgate, 1987; Pitchford, 1977) 
Table 3. Mammalian definitive hosts (other than human) found naturally infected by the human schistosome $S$. haematobium

\section{Hosts}

Primates

Lagomorpha

(Hares, rabbits and picas)

Rodentia

(Rodents)

Carnivora

(meat-eating placental mammals

Cetartiodactyla

(ungulates, such as cows and camels)

Perissodactyla (odd-toed ungulates such as zebras)

Insectivora

(obsolete as a taxonomic order, referred to as insect eaters such as moles)

Xenarthra

Didelphimorphia

(opposums) (placental mammals such as anteaters, tree sloths, and armadillos)

\section{Species}

Cercopithecus aethiops ${ }^{b}$, C. mitis ${ }^{a}, C$. pygerethrus $^{a, c}$, Pan satyrus ${ }^{b}, P$. troglodyts $^{a, c}$, Papio Anubis ${ }^{a, c}, P$. dogera $^{b}$, P. papio ${ }^{a, c}$, P. rhodesiae ${ }^{b}, P$. ursinus $^{a, c}$

None

Arvicanthis niloticus ${ }^{a, d, e}$, Otomys $s p^{f}$

None
${\text { Ovis } \text { aries }^{a, c},}_{\text {Sus scrofa }}^{a, c}$, syncerus
caffer
None
None
None
None

${ }^{\mathrm{a}}$ Rollinson and Southgate, 1987; ${ }^{\mathrm{b}}$ Ouma and Fenwick, 1991; ${ }^{\mathrm{c}}$ Pitchford, 1977; ${ }^{\mathrm{d}}$ Mansour, 1973; ${ }^{\mathrm{e}}$ Mansour, 1978; ${ }^{\mathrm{f}}$ Pitchford 1959 
Table 4. Mammalian definitive hosts (other than human) found naturally infected by human schistosomes $S$. japonicum
Hosts
Species

Primates

Lagomorpha

(Hares, rabbits and picas)

Rodentia

(Rodents)

Carnivora

(meat-eating placental mammals

Cetartiodactyla

(ungulates, such as cows

and camels)

Perissodactyla (odd-toed ungulates such as zebras)

\section{Insectivora}

(obsolete as a taxonomic order, referred to as insect eaters such as moles)

Xenarthra

(placental mammals such as anteaters,

tree sloths, and armadillos)

Didelphimorphia

(opposums)
Macaca fascicularis, M. mulatta

Lepus cuniculus $^{\mathrm{b}}$, L. europaeus $^{\mathrm{a}}{ }^{,}$, L. sinensis ${ }^{\mathrm{a}, \mathrm{c}}$

Apodemus argarius ${ }^{\mathrm{d}}$, A. specious $^{\mathrm{a}}$, Bunomys chrysocomus ${ }^{\mathrm{a}, \mathrm{d}}$, Callosciurus erthraeus $^{\mathrm{a}, \mathrm{d}}$, Eothenomys melanogaster ${ }^{\mathrm{e}}$, Hystrix brachyura ${ }^{\mathrm{a}}$, H. subcristata $^{\mathrm{a}, \mathrm{d}}$, Microtus mandarinus ${ }^{\mathrm{a}, \mathrm{d}}, M_{\text {. montebelli }}{ }^{\mathrm{e}}$, Mus musculus ${ }^{\mathrm{a}}$, Niviventer confucianus $^{\mathrm{d}}, N$. fulvescens ${ }^{\mathrm{a}} \mathrm{d}$, , Rattus chyrscomus $^{\mathrm{e}}, R$. confucianus ${ }^{\mathrm{a}} \mathrm{d}, \mathrm{d}, R$.

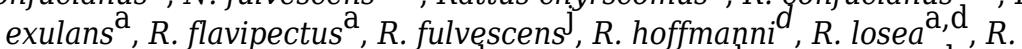
marmosurus $^{\mathrm{a}, \mathrm{e}}$, . nitidus $^{\mathrm{a}} \mathrm{d}$, . norvegicus $^{\mathrm{a}} \mathrm{d}, \mathrm{e}$, R. rattus $^{\mathrm{a}} \mathrm{d}$

Canis familiaris ${ }^{\mathrm{d}, \mathrm{e}, \mathrm{f}}$, Civet $_{\text {cat }}^{\mathrm{a}}$, Felis bengalensis $^{\mathrm{a}, \mathrm{d}}, \mathrm{F}_{\text {. domestica }} \mathrm{d}, \mathrm{f}, \mathrm{F}_{\text {. }}$

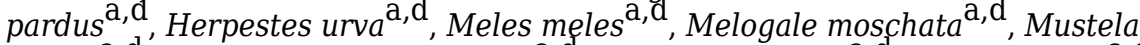
sibirica $^{\mathrm{a}, \mathrm{d}},{ }^{\prime}$ Nyctereutes procyonoides ${ }^{\mathrm{a}} \mathrm{d}$, Viverricula indica ${ }^{\mathrm{a}, \mathrm{d}}$, Vulpes vulpes ${ }^{\mathrm{a}, \mathrm{d}}$

Bos Taurus ${ }^{\mathrm{a}, \mathrm{d}}$, B. buffelus $\mathrm{d}$, Bubalus bubalis ${ }^{\mathrm{e}, \mathrm{f}}$, Capra hicus $\mathrm{d}, \mathrm{f}$ Hydropotes inermis $^{\mathrm{a}, \mathrm{d}}$, Muntiacus reevesi $^{\mathrm{a}, \mathrm{d}}$, Ovis aries ${ }^{\mathrm{d}}$, Sus scrofa ${ }^{\mathrm{a}} \mathrm{d}, \mathrm{e}, \mathrm{f}$, Wild deer $^{\mathrm{a}}$

Equus asinus $^{\mathrm{d}}$, E. equus $^{\mathrm{d}}$

Crocidura attenuate $^{\mathrm{a}, \mathrm{d}}$, Erinaceus europaeus $^{\mathrm{a}, \mathrm{d}}$, Suncus suncus $\mathrm{d}, \mathrm{S}$. mirinus $^{\mathrm{a}}$

None

None

${ }^{\mathrm{a}}$ Rollinson and Southgate, 1987; ${ }^{\mathrm{b}}$ Ouma and Fenwick, 1991; ${ }^{\mathrm{c}}$ Pitchford, 1977; ${ }^{\mathrm{d}}$ Chen, 1993; ${ }^{\mathrm{e}}$ Mott, 1982 ; ${ }^{\mathrm{f}}$ Wang et al., 2005

\subsubsection{Prepatent periods}

In the definitive host, the prepatent period can be defined as the duration between cercarial penetration and output of eggs. This period takes around 6-7 weeks after infection. In the intermediate snail host, the prepatent period is defined as the duration between miracidial penetration in the snail and cercarial shedding. This period takes 28 days for S. mansoni and is longer (45 days) for $S$. haematobium.

\subsubsection{Period of communicability}

\subsubsection{Shedding by the snails}

In schistosomes, the shedding level of the larvae responsible for human infections is called cercarial production, i.e. the number of larvae produced per snail per day. This number is highly variable, from a few to thousands of cercariae per day. Cercarial production during the patent period follows a sinuous rhythm alternating high and low production phases. This corresponds to the 
duration of the development of a new cercarial generation in the daughter sporocysts, 28 days in $S$. mansoni (Théron and Moné, 1984). The snail in which the parasite develops influences the production rhythm. For example, in $S$. bovis, cercarial production during the patent period followed one big peak only when the cercariae developed in Bulinus but followed a sinuous rhythm when larval development occurred in Planorbarius metidjensis, alternating with periods of high and low production (Mouahid and Théron, 1986).

The snail in which the parasite develops influences the quantity of cercariae produced: for example, in $S$. mansoni after 13 weeks of shedding, total cercarial production was 38,000 cercariae per snail in the $S$. mansoni/B. glabrata interaction (Moné et al., 1986) compared to 11,700 cercariae per snail in the $S$. mansoni/B. pfeifferi interaction (Mintsa-Nguéma, 2010).

Shedding levels may also vary according to the environment of the snail hosts. For example, the cercarial

production of $S$. mansoni by $B$. glabrata was up to three times higher when other snails (non-target snails which are non-hosts for schistosomiasis) were present together with the infected vector snails during the patent period (Moné et al., 1986). Furthermore, a positive correlation was found between cercarial productivity and vector snail growth (Moné, 1991); this author showed that the influence of the non-target snails acted directly on the host snail vector by stimulation of its metabolism, increasing the parasite's biotic capacity.

\subsubsection{Timing of snail shedding}

Shedding time in schistosomes is a very important parameter because cercariae have adapted their shedding out of the snails to coincide with the aquatic behavior of their definitive hosts; the shedding behavior is also called chronobiology, it enhances parasite transmission using localization in the 'host-time' (Combes et al.,1994). Cercarial emergence rhythm has been proven to be genetically determined (Théron and Combes, 1988).
Cercarial shedding patterns vary according to the water usage behaviors of the desired host as summarized in Figure 8. S. bovis, a bovine schistosome, sheds its cercariae early in the morning when the bovine target is going to freshwater to drink; S. margrebowiei, a wild ungulates schistosome, sheds its cercariae both in the early morning and in the late afternoon when these animals go to relieve their thirst; on the contrary, S. rodhaini, a specialist of rodents, sheds its cercariae by night when the nocturnal rodent targets are available. Interestingly, all human schistosomes have adapted themselves to human behavior and shed their cercariae from the late morning to the afternoon when human targets use freshwater for multiple uses including bathing, fishing, washing, recreation and other purposes. Nevertheless, some of these species may also use other vertebrate hosts and adapt their behaviors to those hosts. The species S. mansoni, which is primarily known as a human schistosome, is a good example of this phenomenon because it also uses rodents as vertebrate definitive hosts. The adaptation of this species to the behavior of its hosts is exemplary: in Guadeloupe, the populations using human hosts primarily shed their cercariae with an average emergence peak around noon, the ones using a rodent host, Rattus rattus, shed their cercariae with an average emergence peak around $4 \mathrm{pm}$. Interestingly, when snails are infected by both strains, the shedding pattern of each is conserved (Théron et al., 1997). Infection of snails by more than one species of schistosome is possible and each species keeps its proper rhythm. For example, S. bovis and $\mathrm{S}$. haematobium may occur in the same Bulinus individual. In experimentally mixed infections, the average emergence peaks were 8 am and noon for S. bovis and S. haematobium, respectively (Mouahid et al., 1991). More recently, another more extreme dichotomous behavior was found in the Sultanate of Oman where one population of S. mansoni using the human host sheds its larvae with an average emergence peak at noon principally and one population of S. mansoni which uses Rattus rattus as definitive host sheds its larvae at night with an average emergence peak at 8pm (Mouahid et al., 2012). This new behavior from $\mathrm{S}$. mansoni enhances the timing possibilities of this species to infect a host.

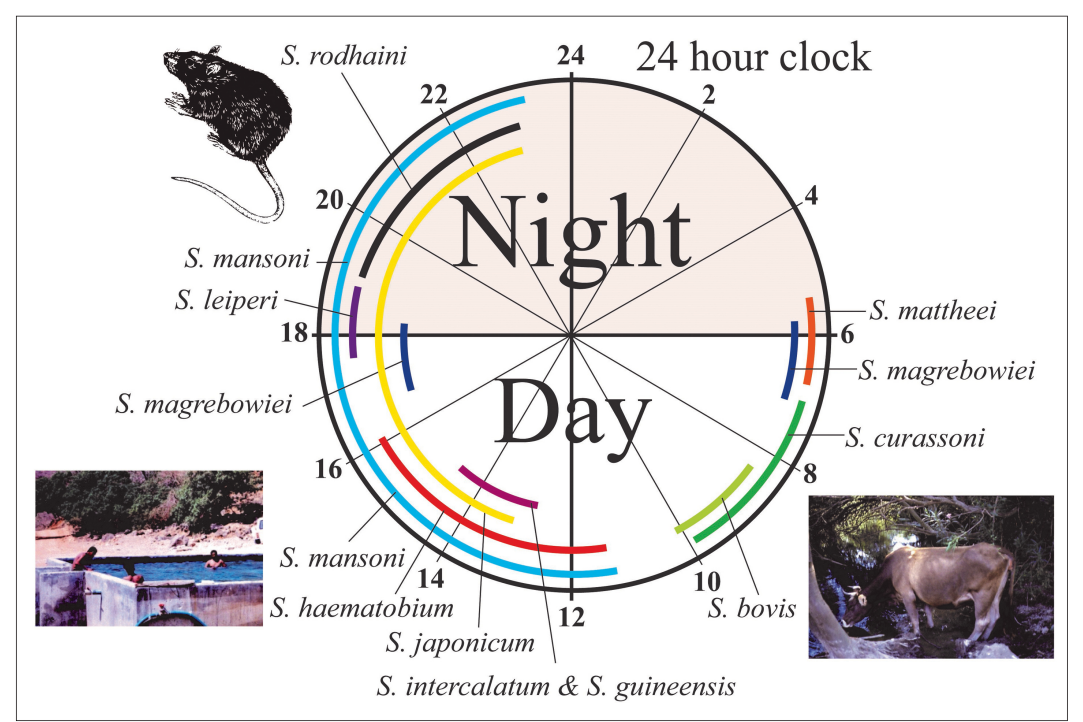

Figure 8. Temporal extent of the daily cercarial emission in some Schistosoma species: S. mattheei (Pitchford et al., 1969), S. margrebowiei (Raymond and Probert, 1991), S. curassoni (Mouchet et al., 1992), S. bovis (Mouahid and Théron, 1986), S. intercalatum and S. guineensis (Pagès and Théron, 1990), S. japonicum (Su et al., 2013), S. haematobium (Mouahid et al., 1991), S. mansoni diurnal and nocturnal chronotypes (Théron and Combes, 1988; Mouahid et al., 2012), S. leiperi (Pitchford and Du Toit, 1976), S. rodhaini (Théron, 1989). 
Cercarial shedding polymorphism has not been shown to be correlated with the species of snail infected by $S$. haematobium (N'Goran et al., 1997) or S. mansoni (Favre et al., 1995). However, a correlation has been found between chronobiology and eco-geography (forest versus savanna zones) in S. haematobium, indicating a possible sensitivity to light intensity (N'Goran et al., 1997; Mintsa-Nguéma et al., 2014).

\subsubsection{Distributions in human tissue}

In high endemic areas, presumably, individuals are frequently re-infected when they come into contact with cercariae emitted by infected snails. Penetration is active and occurs through the skin (Figure 9). After penetration, each cercaria becomes a schistosomulum after different changes: loss of tail, kicking out the preacetabular glands, loss of the cercarial glycocalyx, acquiring double belayer outer membrane. It takes greater than 80 hours post infection to leave the dermis via the venous circulatory system and to reach the lungs through the right heart (Gobert et al., 2007; Wilson, 2009). The arrival to the lungs takes 4 to 10 days. Schistosomula leave the lungs towards the left heart, go to the liver through the hepatic artery and mate in the venous system. Mating will initiate the development to sexual maturity: the female, much thinner than the male, engages in the male gynaecophoral canal where she is protected and is transported by the male to above or below mesenteric veins (Figures 10 and 11) for intestinal schistosomes (S. mansoni, S. japonicum, S. mekongi, S. intercalatum and S. guineensis) and to bladder venous plexus for S. haematobium. The arrival of the pairs in the nesting sites occurs 5-6 weeks after penetration. The eggs are laid and need to cross the vessel wall and the wall of the intestines or bladder to be expelled outside in the stool or in the urine depending on the
Schistosoma species. Turner et al. (2012) revealed that S. mansoni females exploit Peyer's Patch lymphoid tissue (PP) as a preferential route of egress for their eggs. They showed that egg deposition is more abundant within PP-associated vasculature. Passing through the PP allows the eggs to easily access the intestinal lumen to be evacuated with the stool. This facilitates the transmission of the parasite and reduces host morbidity. However, a significant proportion of eggs fails to cross the two barriers and are trapped in the surrounding tissues of target organs (intestine,and bladder) or is carried in the bloodstream (Figures 10 and 12) to other organs such as liver, lungs, kidneys and central nervous system causing high morbidity (Gryseels et al., 2006). The presence of eggs in the central nervous system is named neuroschistosomiasis (Ross et al., 2012). In the brain, granulomas formed around the eggs are associated with epileptic convulsions and/or blurred vision; at the level of the spinal cord, the eggs are responsible for transverse myelitis (spinal compression) with motor weakness, alterations in sensitivity even cases of paralysis and lumbar and sacral myelopathy or urinary incontinence (Ross et al., 2012). Neuroschistosomiasis can occur with S. haematobium (Imai et al., 2011), S. mansoni (Scrimgeour et al., 2001) and S. japonicum ( $\mathrm{Li}$ et al., 2011) infections. Its true prevalence is yet unknown but is presently estimated at between $1 \%$ and $5 \%$ of all diagnosed cases of schistosomiasis (Ross et al., 2012).

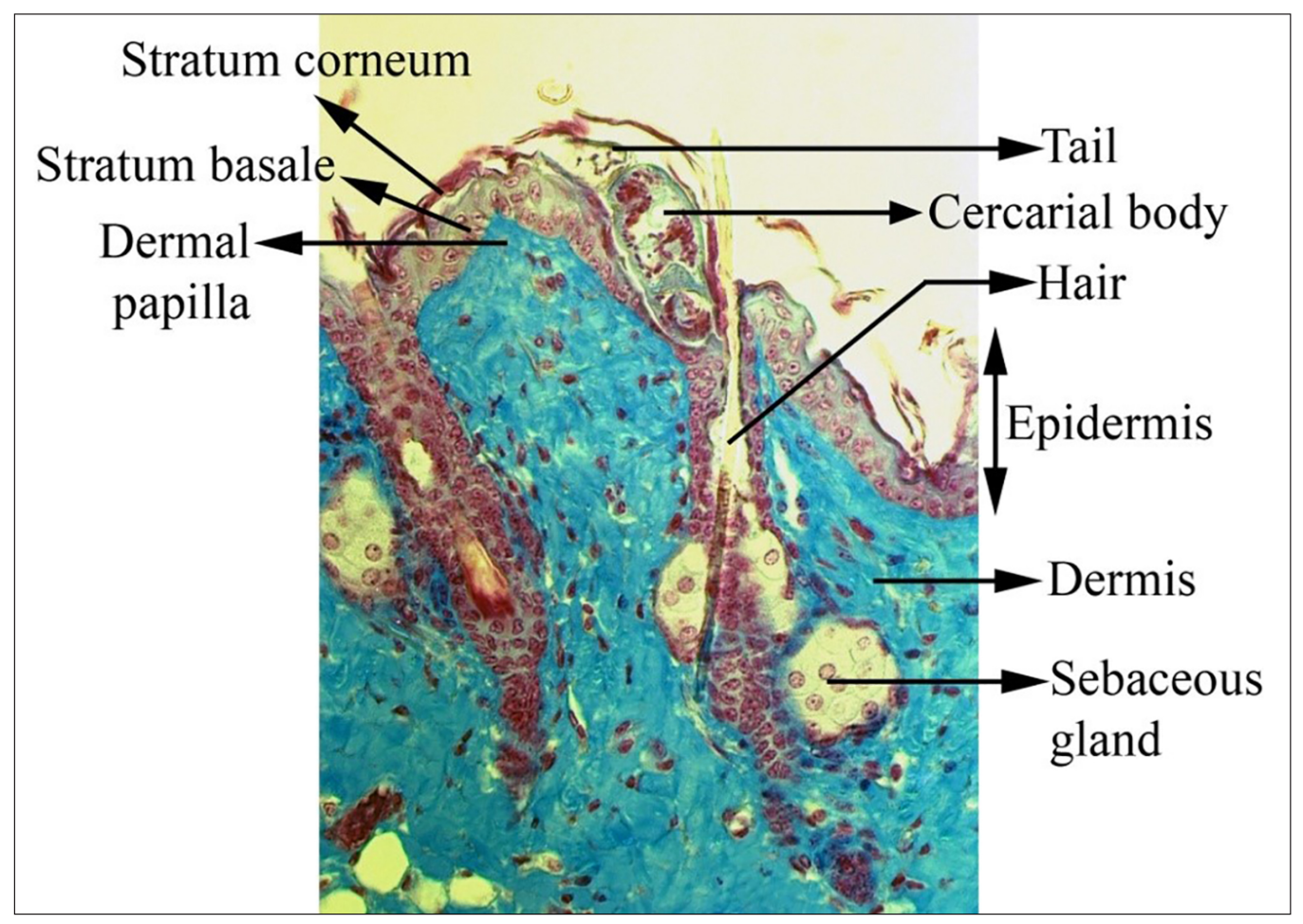

Figure 9. Histological section of the integument of a rodent showing a S. mansoni cercaria penetrating the skin at the exit of the hair 


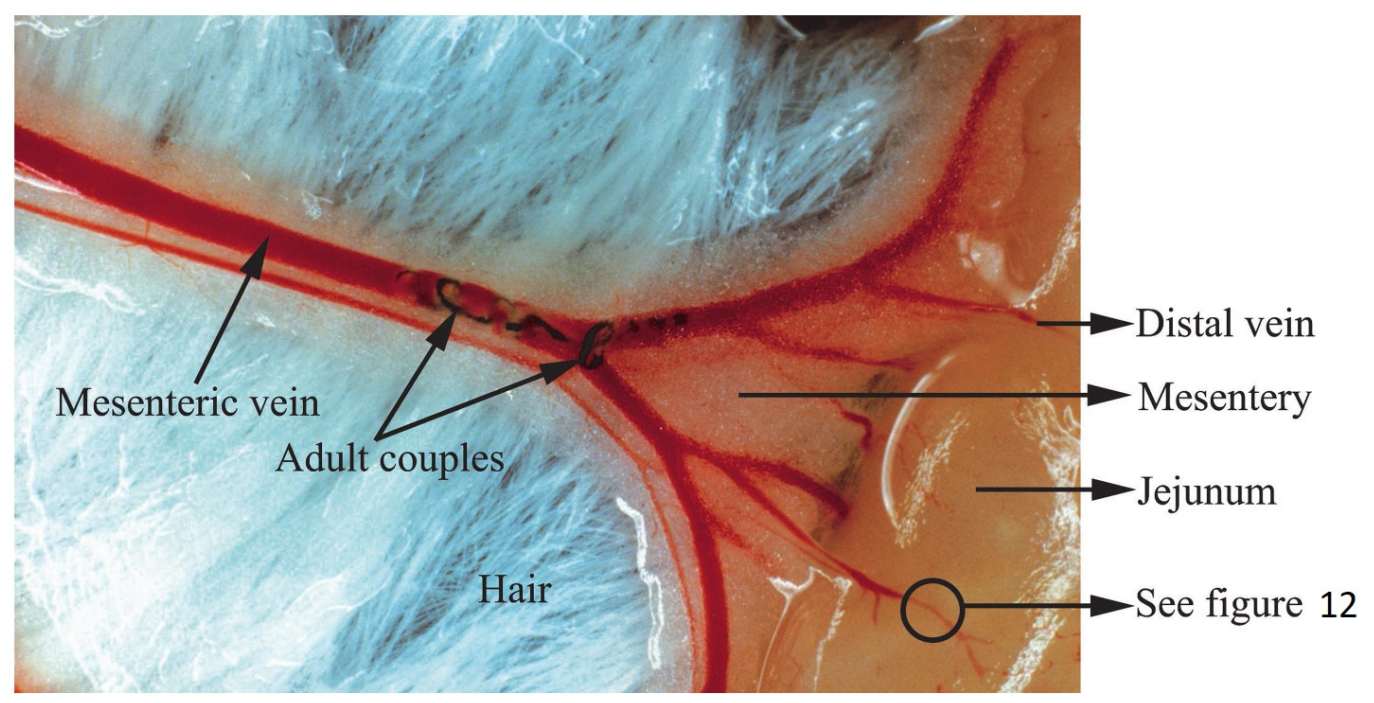

Figure 10. Coupled $S$. mansoni adults in the mesenteric veins of the small intestine (jejunum) of an experimentally infected mouse. Females feed on large amounts of red blood cells per day and lay large numbers of eggs. Females are easily identifiable by their black pigmentation as a result of red blood cell digestion by-products in their digestive tracts.

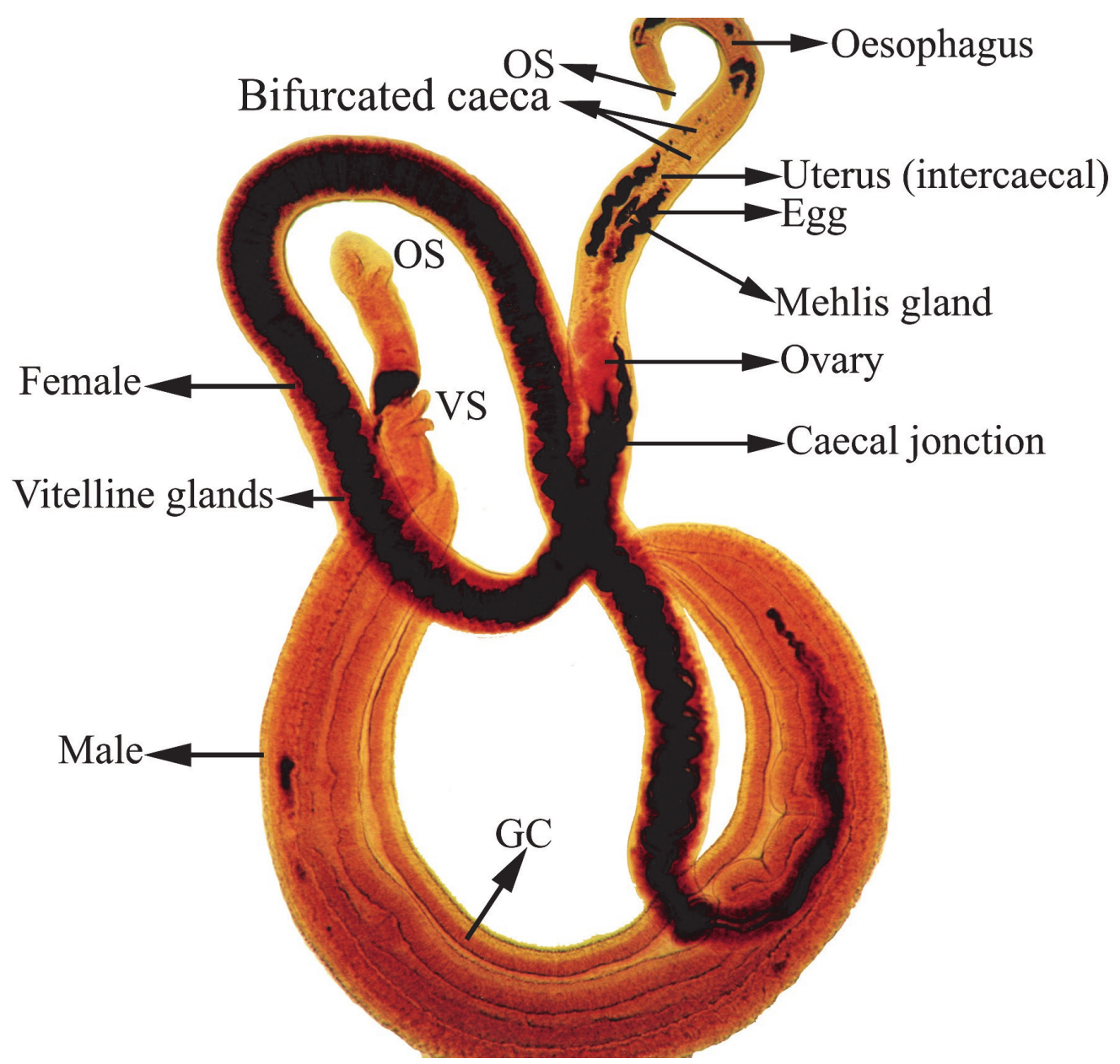

Figure 11. Schistosoma mansoni adult pair collected at the mesenteric vein of an experimentally-infected mouse. The female appears thin and stringy with its posterior part still in the gynecophoric canal (GC) of the male. We can easily distinguish female organs such as the uterus with one egg in the ootype, the vitelline glands throughout the body on each side of the common caecum. Each worm has an oral sucker(OS) which also serves as mouth and ventral sucker (VS) or acetabulum which serves as a fixation organ. 


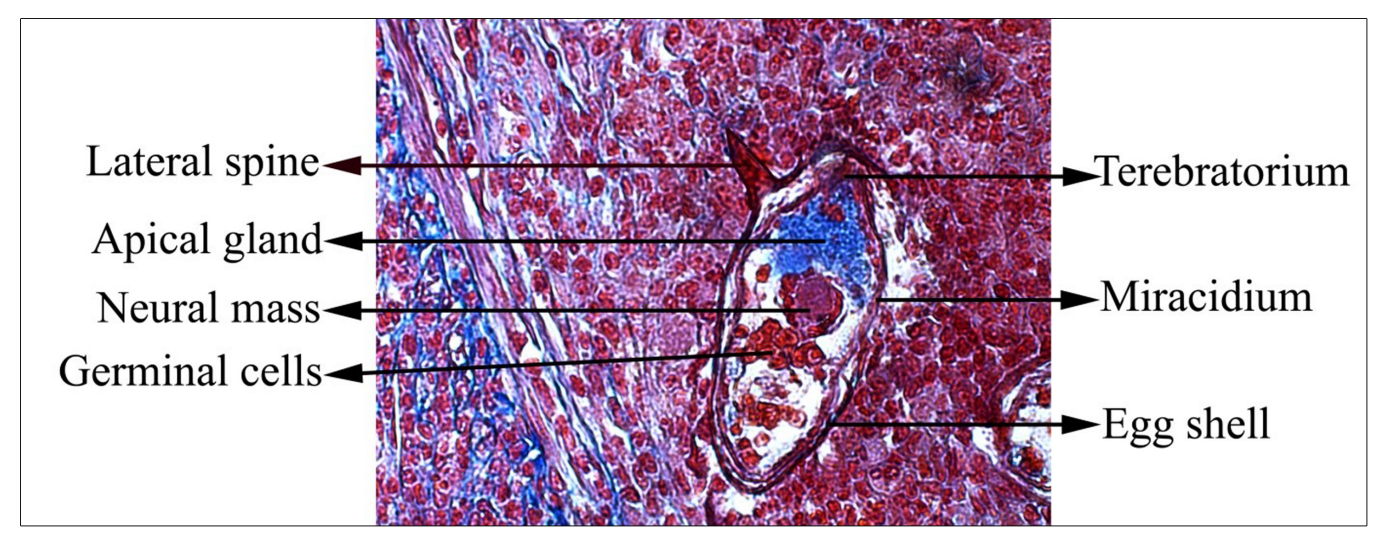

Figure 12. Schistosoma mansoni mature egg in a distal vein of the jejunum in an experimentally-infected mouse. The egg contains a well-developed miracidium where various structures are visible including germinal cells that will develop in the snail intermediate host to become mother sporocysts.

\subsubsection{Population susceptibility}

Human population susceptibility towards schistosomiasis is under the control of several factors related to the environment, to the human host (sex, age, time contact with infected water, etc.), to the parasite (density of parasites in the transmission sites, cercarial shedding pattern), to the snail vector (prevalence $=\%$ of infected snails) and to the reservoir hosts (Isnard and Chevillard, 2008). Resistance to re-infection by schistosomes has been widely debated and current work showed that it does develop, although it may take a long time (Colley and Secor, 2014). In Uganda, at Albert Lake, fishing communities are more prone to infection than children. However, after treatment with Praziquantel, the level of reinfection is the same in adults and children. The authors interpreted these results by suggesting a better physiological or even immunological resistance in adults compared to children. (Kabatereine et al., 1999). In Kenya, Melman et al. (2009) found that schistosomes from previously treated patients with Praziquantel were significantly less susceptible than those that were not. Also, schistosomes derived from a single patient who had been treated with Praziquantel 18 times showed marked resistance.

Susceptibility/resistance to schistosomiasis depends on genetic factors; for example in an endemic area of Brazil, individuals highly infected with $S$. mansoni belonged to some families and were not randomly distributed in the population (Abel et al., 1991). Various genetic analyzes (segregation analysis, linkage disequilibrium, multivariate linear regression analysis) conducted on Brazilian families infected by S. mansoni (Marquet et al., 1996) and on Malian families infected by $S$. haematobium (Isnard and Chevillard, 2008) showed that the polymorphisms of the IL-13 (interleukin) and STAT6 genes were strongly and synergistically involved in controlling the level of infection. Both genes are located respectively on the 5 q31 chromosome (where there are the genes involved in the immune response as those encoding interleukins (IL-4, IL-5, IL-9 and IL-13) and interferon) and on the 12 q13 chromosome. Very recently a functional polymorphism of
IL-13 with one allele (IL-13 SNP rs1800925T) associated with a strong risk of developing liver fibrosis by increasing the expression level of IL-13 protein by Th2 cells was found among China's population infected by $S$. japonicum in chronic phase (Long et al., 2015). Then it is now admitted that the intensity of Schistosoma infection in humans is markedly influenced by host genetics. King et al. (2004) showed that among long-established populations of coastal Kenya (Province Wadigo), heritable variation in host susceptibility was low, and likely played a minimal role in determining individual risk for infection or disease. Their study suggested a limited heritable component of risk for infection intensity with $S$. haematobium in a highly endemic setting. Just like human host genetics impact the establishment of a successful infection so to do snail host genetics as is seen in the susceptibility of snail population vectors (Biomphalaria or Bulinus) towards allo - versus sympatric Schistosoma species. In $S$. mansoni, the sympatric association with $B$. pfeifferi in Benin showed the existence of a good host-parasite compatibility resulting in faster parasite development, moderate cercarial production accompanied by a strong survival of the sympatric snail (Ibikounlé et al., 2012). In S. haematobium, the sympatric association with Bulinus globosus in Benin showed good host-parasite compatibility resulting in a shorter prepatent period, a longer patent period and a high cercarial production in local snail (Ibikounlé et al., 2013). In both cases, the authors considered the possibility of a local adaptation. Finally, a phenotypic and genotypic experimental study in a context of mutual impact on the fitness of $S$. mansoni and its snail vector Biomphalaria (susceptible or resistant) showed that the parasites adapt very quickly to the snails that have been selected over generations for resistance to schistosomes (Webster et al., 2007).

The intermediate snail hosts of schistosomes are known to have an internal defense system with both cellular and humoral components engaged in protecting the snail from infection. (Yoshino et al., 2016). Immune cells circulating in the hemolymph are called hemocytes and plasma (hemolymph without cells) contains various humoral factors such as recognition receptors (lectin-like proteins, called 
fibrinogen-related proteins (FREPs) (Adema et al., 1997), aggregation factors and other molecules such as proteases, stress proteins and antibacterial peptides. Resistant snails are able to recognize the parasite and to build a capsule where it disintegrates gradually. In this situation, the hostparasite combination is considered incompatible. When recognition of the parasite does not occur or is insufficient, the parasite develops; the snail is considered as susceptible and the host-parasite combination is considered compatible (Coustau et al., 2015). In compatible combinations, the parasite produces various highly polymorphic proteins called $S$. mansoni polymorphic mucins (SmPoMuc). These mucins have a protective function during the miracidium metamorphosis to mother sporocyst (Roger et al., 2008). They form immune complexes with a specific set of highly variable immune receptors (Fibrinogen Related Proteins : FREPS) of the snail Biomphalaria glabrata (Mone et al., 2010; Mitta et al., 2012; Dheilly et al., 2015). In an incompatible combination, an immune complex formed by FREPs_SmPoMuc and opsonine allows hemocytes to recognize the parasite and initiate cell encapsulation (Yoshino et al., 2016).

\subsection{Population and Individual Control Measures}

\subsubsection{Treatment options}

Praziquantel (acylated quinoline-pyrazine) is the only WHO-recommended anthelminthic drug available for use in preventive chemotherapy of schistosomiasis (WHO, 2006). Estimates show that at least 218 million people required preventive treatment for schistosomiasis in 2015 and only about 66.5 million people (30.5\%) were reported to have been treated for schistosomiasis in 2015 (WHO, 2017b). Even if progress is made to reduce or even prevent morbidity, additional methods such as sanitation, hygiene education, access to water and snail control are needed to adequately control schistosomiasis. A strategic plan (2012-2020) was provided by WHO (WHO, 2013) presenting a vision of a world free of schistosomiasis. Schistosomiasisendemic countries should progressively scale up their objective from control of morbidity by 2020 through chemotherapy with Praziquantel, to elimination as a publichealth problem by 2025 through preventive chemotherapy and complementary public-health interventions. To eventually achieve interruption of transmission (reducing incidence of infection to zero) by 2025, schistosomiasisendemic countries should intensify preventive chemotherapy, provision of potable water to prevent at-risk water contact, adequate sanitation to reduce contamination of water bodies and snail control to eliminate the snail intermediate host. The status of the 78 countries that are endemic for schistosomiasis is the following: 52 currently require implementation of preventive chemotherapy (for example Benin in the WHO African Region), 7 require updating of their schistosomiasis status for planning and implementation purposes (for example Oman in the WHO Eastern Mediterranean Region) and 19 require evaluation of their schistosomiasis status in order to verify if interruption of transmission has already been achieved (for example Guadeloupe in the WHO Region of the Americas) (WHO, 2013).
The WHA 65.21 resolution of the World Health Assembly for elimination of schistosomiasis (WHO, 2012) calls on all countries endemic for schistosomiasis (i) to analyse and develop applicable plans with progressive targets, to intensify control interventions and to strengthen surveillance; (ii) to improve the environment in order to cut the transmission of schistosomiasis and accelerate the elimination of the intermediate host; (iii) to ensure the provision of essential medecines. The WHA 65.21 resolution requests the Director General (i) to elaborate a procedure to evaluate the interruption of transmission of schistosomiasis in the countries concerned with a view to certifying that transmission has been eliminated in these countries; (ii) to support, during the post-elimination phase, countries that have been certified free of schistosomiasis to pursue preventive actions to avoid the reintroduction of transmision of the disease.

\subsubsection{Vaccines-including in other hosts than humans}

Vaccine clinical development is a three-phase process (CDC, 2015). During Phase I clinical trials, small groups of people receive the trial vaccine. In Phase II, the clinical study is expanded and vaccine is given to people who have characteristics similar to those for whom the new vaccine is intended (such as age and physical health). In Phase III, the vaccine is given to thousands of people and tested for efficacy and safety.

The aim of vaccination against schistosomiasis is to drastically limit the transmission of the parasite to humans by preventing the schistosomules from continuing their development and becoming adults (Merrifield et al., 2016). The target species of schistosomes are mainly $S$. haematobium (urogenital schistosomiasis) and $S$. mansoni (intestinal schistosomiasis). These two species account for almost $99 \%$ of the world cases.

Three vaccine candidates have been tested in clinical trials, Bilhvax (28-kDa recombinant glutathione-Stransferase) for $S$. haematobium and Sm-TSP-2 and Sm-14 for $S$. mansoni. Bilhvax underwent phases 1 and 2 clinical trials in Senegal (Beniguel et al., 2003; Riveau et al., 2012), and the results of phase 3 are pending (see ClinicalTrials.gov Identifier: NCT00870649) (ClinicalTrials.gov, 2017a). Sm-TSP-2 (9-kDa recombinant tetraspanin) for S. mansoni underwent phase 1 clinical trials in Houston, Texas, USA (Tran et al., 2006; Cheng et al., 2013; ClinicalTrials.gov, 2017b) (see ClinicalTrials.gov Identifier: NCT02337855). Sm-14 (14-kDa recombinant fatty acid binding protein) for $S$. mansoni underwent phase 1 trial (Santini-Oliveira et al., 2016) and phase 2 trials are ongoing in Brazil (see ClinicalTrials.gov Identifier: NCT03041766) (ClinicalTrials.gov 2017c).

There are also vaccine candidates in development for $S$. japonicum as well. Da'Dara et al. showed that vaccination of water buffaloes with the DNA-based vaccines SjC23Hsp70, SjC23 plasmids, SjCTPI-Hsp70 and SjCTPI plasmids, in addition to treatment with Praziquantel, reduced the numbers of egg-laying parasites in livestock, leading to measurable declines in prevalence, intensity and transmission of S. japonicum. More generally, each 
intervention that reduces schistosome infection in domestic reservoir hosts will enhance their health simultaneously reducing disease transmission to humans (Da'dara et al. 2008).

No effective vaccine is available to prevent schistosomiasis in the short term, despite a large panel of 97 antigen candidates having been tested over the previous decades (McManus and Loukas, 2008). However, the major advances in schistosome molecular biology (OMICs databases) will allow to identify new vaccine candidates (Ricciardi and Ndao, 2015; Merrifield et al., 2016).

\subsubsection{Hygiene measures}

The WHA 65.21 resolution of the World Health Assembly for elimination of schistosomiasis (WHO, 2012) encouraged water, sanitation, and hygiene (WASH) interventions as components of an integrated control. Here are the definitions of access to water and sanitation according to WHO-UNICEF Joint Monitoring Programme (WHO and UNICEF, 2015): 1. An improved drinking-water source is one that, by the nature of its construction and when properly used, adequately protects the source from outside contamination, particularly faecal matter (piped water into dwelling, piped water to yard/plot, public tap or standpipe, protected dug well, protected spring, etc.); 2 . An improved sanitation facility is one that hygienically separates human excreta from human contact (flush toilet, piped sewer system, septic tank, flush/pour flush to pit latrine, composting toilet, etc.). Hygiene promotion cannot be reduced to cleanness promotion. According to the WHO, Hygiene refers to conditions and practices that help to maintain health and prevent the spread of diseases (WHO, 2017a).

Transmission to humans is based on the contact of the human skin with the cercariae shed from the snail host; blocking transmission could consist in avoiding any contact with water containing these larvae. However, everyday activities put people at risk for exposure to the parasite; they include laundering, fishing, bathing, and swimming, or any other activity that exposes skin to water containing cercariae. Providing a safe water supply is not sufficient to block transmission if those activities continue. Sanitation efforts should be aimed at preventing the contamination of freshwater with urine and/or feces.

A systematic review was recently published on the relationship between water, sanitation and schistosomiasis (Grimes et al., 2015). These authors showed that the access to safe water supplies is associated with significantly less infection with $S$. haematobium, S. mansoni and $S$. japonicum while adequate sanitation was found to be associated with significantly less infection with both $S$. haematobium and $S$. mansoni. No observational studies were found assessing the association between good hygiene, defined as the use of soap during water contact, and Schistosoma infection. Socioeconomic status (SES) can also affect the transmission of schistosomiasis. For instance, one of the SES indicator is the type of housebuilding material used: stone/redbrick or mudbrick (sunbaked)/mud (Farooq et al., 1966b). The stone/redbrick houses are predominant in urban areas and the mudbrick/mud houses are predominant in rural areas. These authors showed that the prevalence rates of $S$. haematobium and $S$. mansoni were considerably higher for persons living in houses constructed of mudbrick or mud.

\subsection{Environmental Occurrence and Persistence}

\subsection{Detection Methods}

The ability to detect the presence of parasite in water bodies may help in planning control schemes.

\subsubsection{Detection of free larval stages}

Different methods have been used to detect the presence of cercariae in water based on differential filtration technique, a succession of sieves (Théron, 1979; Kloos et al., 1982; Prentice, 1984), the use of positive phototropism of cercariae (Sandt, 1972) or traps with unsaturated fatty acid as cercarial attractant (Shiff et al., 1993; Ahmed et al., 2002). All these methods have been applied in standing water and have not been improved in moving water. Moreover they give more qualitative than quantitative information. The fact that some of these methods were developed upwards of 50 years ago and are not and have not been used in control programs also demonstrates their poor reliability.

The use of sentinel snails allows to trap miracidia (infecting larval stages for snails) in transmission sites. To identify the trapped parasites, PCR diagnosis should be used (Allan et al., 2013). Recently, environmental DNA methods have been tested. These assays are based on the detection of schistosome DNA in surface water, and hence enabling direct measure of infection risk/transmission. Environmental DNA (eDNA) is widely used in aquatic ecology for the detection of invasive species, species of interest, or to evaluate ecosystem biodiversity (Bohmann et al., 2014). For parasitological purposes such methods are promising for the detection of both parasites and vectors (Worrell et al., 2011; Bass et al., 2015). eDNA has been successfully used for the detection of trematode parasites of frogs (Huver et al., 2015). Moreover, it has successfully been used to detect bird schistosomes and $S$. japonicum in surface water in endemic areas (Hung and Remais, 2008; Schets et al., 2010; Worrell et al., 2011).

\subsubsection{Detection of infected snails}

The snail intermediate hosts of the significant schistosomes that infect human belong to 4 genera: Biomphalaria for S. mansoni, Bulinus for S. haematobium, Oncomelania for $S$. japonicum and Neotricula for $S$. mekongi. The snail vectors may coexist in a given transmission site with other non-vector snails. Positive snails can be identified in different ways. 1 . When shell transparency permits, trematode daughter sporocysts can be seen under the binocular microscope and thus identify the infected snails (see Figure 2 for Biomphalaria glabrata infected by $S$. mansoni). However, there is no certainty that 
these are schistosomes. 2. The collected snails are individually isolated in small containers with spring water during two consecutive periods of $12 \mathrm{~h}$ light and $12 \mathrm{~h}$ dark. At the end of each period, check under the binocular microscope for the presence of schistosome cercariae (See Figures 5 and 8; S. mansoni cercarial emission can occur during the day or during the night period). It is clear that biologists need to be able to identify both the right snail species and the right cercariae and not be confused by other cercariae because the target snails are also vectors of other trematodes. However, there is no certainty as to the identity of the schistosome species. Indeed, the same snail genus can be the intermediate host of several species of schistosomes. For example, the genus Bulinus is the intermediate host of 9 species: $S$. bovis, $S$. curassoni, $S$. guineensis, S. haematobium, S. intercalatum, S. leiperi, $S$. kisumuensis, S. margrebowiei, S. mattheei. 3. Hamburger's group developed molecular detection of snail schistosomiasis infection based on PCR assays of Sm1-7 repeated sequence of $S$. mansoni (Hamburger et al., 1991; Abbasi et al., 2010) and of Dra1 repeated sequence (Accession number DQ157698.1) of S. haematobium (Hamburger et al., 2001; Abbasi et al., 2010). However, the Dra1 is not specific to $S$. haematobium that is why Dra1 needs to be used together with SmS1/Sh110 (Abbasi et al., 2010) The use of these techniques in natural transmission areas has remained very limited probably because of the lack of well-trained people and financial resources.

\subsection{Data on Occurrence in the Environment}

The occurrence of schistosomiasis in various endemic countries is influenced by several components, including climate seasons (wet season and dry season), sanitation, access to drinking water, snail distribution, distribution of reservoir hosts, and socio-cultural factors that determine human behavior (Kloos et al., 2010). Indeed, the level of human contact with water determines the frequency and intensity of exposure to cercariae in transmission foci. For example, Farooq et al. (1966a) have shown in Egypt that Muslims, due to the ritual ablutions to which they are held and which they practice mainly in the irrigation canals, have infection rates more than twice as high as those of Christians. The free movement of populations in ECOWAS countries in West Africa favors an increase in the range of distribution of schistosome species and increases the possibilities of hybridization between related species (terminal egg spine schistosomes). The recent presence of bilharziasis in Corsica is of Senegalese origin with a crossbreeding with $S$. bovis (Boissier et al., 2016). To predict the risks of small- and large-scale transmission, an increasing number of studies have used different factors to estimate geographic distributions using Bayesian inference methods
(Brooker, 2007). These tools prove constructive to carry out studies of dynamic epidemiology with presentation of geographical maps that highlight zones at risk in relation to space and time (Gomes et al., 2014). Such approaches would enable affected countries to more effectively implement intervention strategies such as avoiding breeding sites becoming true transmission sites.

The occurrence of schistosomiasis is also related to societal factors. The anti-poverty movement called The Millenium Development Goals helped to lift more than one billion people out of extreme poverty from 2000 to 2015, to make inroads against hunger, to enable more girls to attend school than ever before and to protect our planet (UnitedNations, 2015). It was based on eight goals; an example of success will be given below for each goal. The first goal was to eradicate extreme poverty and hunger: the extreme poverty rate in developing countries declined significantly from $47 \%$ to $14 \%$ between 1990 and 2015 . The second goal was to achieve universal primary education: the global number of out-of-school children of primary school age declined by almost half from 100 million to 57 million between 2000 and 2015. The third goal was to promote gender equality and empower women: a majority of regions have reached gender parity in primary education from 1990 to 2015, but disparities persist at higher levels, especially in Sub-Saharan Africa. The fourth goal was to reduce child mortality: the number of deaths of children under five has declined from 12.7 million in 1990 to almost 6 million in 2015 globally. The fifth goal was to improve maternal health: in Southern Asia, the maternal mortality ratio declined by 64 per cent between 1990 and 2013, and in Sub-Saharan Africa it fell by 49 per cent. The sixth goal was to combat HIV/AIDS, malaria and other diseases: over 6.2 million malaria deaths have been averted between 2000 and 2015, primarily of children under five years of age in Sub-Saharan Africa. The global malaria incidence rate has fallen by an estimated 37 per cent and the mortality rate by $58 \%$. The seventh goal was to ensure environmental sustainability: of the 2.6 billion people who have gained access to improved drinking water since 1990, 1.9 billion gained access to piped drinking water on premises. Worldwide, 2.1 billion people have gained access to improved sanitation. The eighth goal was to develop a global partnership for development: official development assistance from developed countries increased by 66 per cent in real terms between 2000 and 2014, reaching $\$ 135.2$ billion. Progressive elimination of inequalities in access and service levels will continue to be an important focus for the post-2015 agenda (United-Nations, 2015). 


\subsubsection{Excreta in environment}

Open defecation exists when human feces are disposed of in fields, forest, bushes, open waterbodies, beaches or other open spaces or disposed of with solid waste (WHO and UNICEF, 2014). The proportion of people practicing open defecation has fallen almost by half since 1990. However, in 2015, 2.4 billion people are still using unimproved sanitation facilities, including 946 million people who are still practicing open defecation (UnitedNations, 2015). For the populations of Sub-Saharan Africa, open defecation was 36\% in 1990 and was still 23\% in 2015 (WHO and UNICEF, 2015). For example in Benin, a country requiring the implementation of preventive chemotherapy, the percentage of open defecation between 1999 and 2015 was respectively $51 \%$ and $25 \%$ in urban localities and $95 \%$ and $76 \%$ in rural localities (in total $79 \%$ in 1990 and still $53 \%$ in 2015) (WHO and UNICEF, 2015). Figure 13 shows a house in a Lake Village in Benin where toilets are on stilts allowing feces and urine to reach the Lake directly. However, in the populations of Western Asia, the percentage of open defecation between 1999 and 2015 reached $0 \%$ whatever the type of localities urban or rural localities. For example in Oman, a country that requires updating of its schistosomiasis status for planning and implementation purposes, open defecation was $15 \%$ in 1990 and 3\% only in 2015 (WHO and UNICEF, 2015). Hygienic bathing after open defecation is also a major factor in the transmission of S. mansoni. Sow et al. showed in Senegal, where culturally it is inappropriate to defecate directly into the waterbodies, that hygienic bathing after defecation of human population of 1000 individuals releases approximately 30,000 miracidia per day, which is equivalent to 12 complete stools entering the water (around 2,500 miracidia per stool) (Sow et al., 2008).

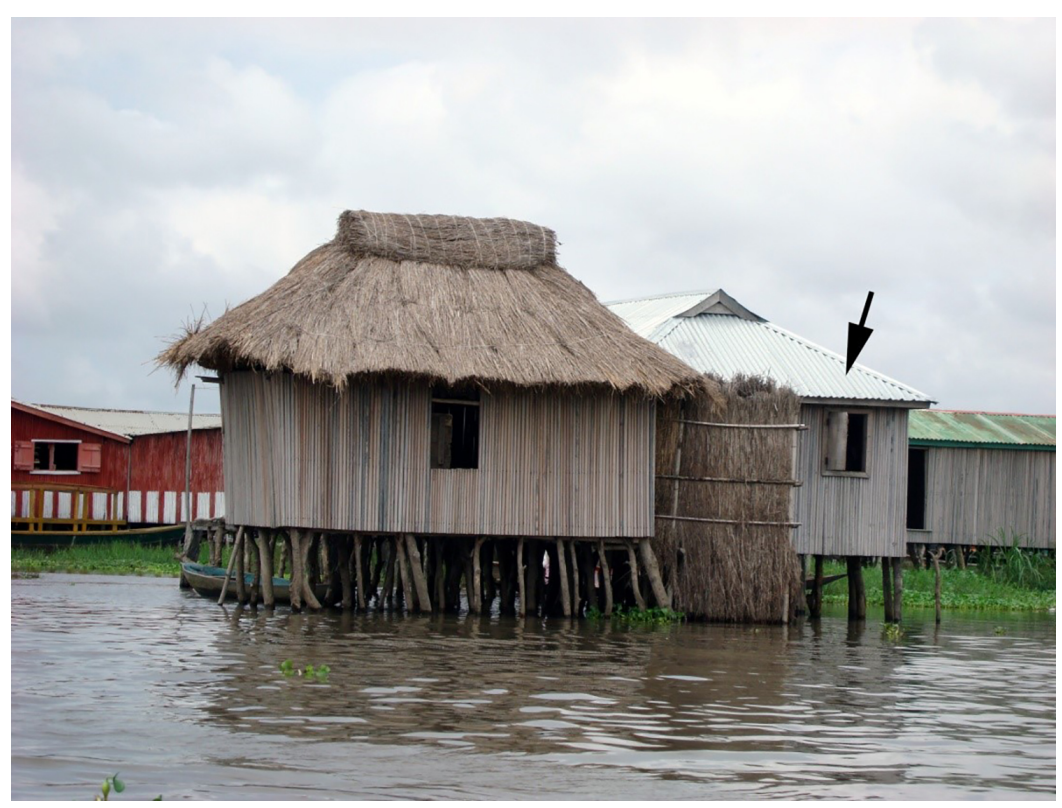

Figure 13. Toilets (Arrow) on stilts on the right of the house in Nokoué Lake (Southern Benin, Africa)

Unimproved sanitation facilities other than open defecation exist when there is no hygienic separation of human excreta from human contact; they include pit latrines without a slab, hanging latrines and bucket latrines (WHO and UNICEF, 2015). The proportion of people using unimproved sanitation facilities was $26 \%$ in 1990 and $27 \%$ in 2015 in the populations of Sub-Saharan Africa. For example, in Benin, it was $8 \%$ in 1990 and still $8 \%$ in 2012 (WHO and UNICEF, 2015). The proportion of people using unimproved sanitation facilities was $10 \%$ in 1990 and $2 \%$ only in 2015 in the populations of Western Asia. For example, in Oman, it was 3\% in 1990 and 0\% in 2015 (WHO and UNICEF, 2015).

\subsubsection{In surface waters, in drinking water}

Surface waters include rivers, dams, lakes, ponds, streams and irrigation channels and unimproved drinking waters include unprotected sources of water and also surface waters (WHO and UNICEF, 2015). 663 million people worldwide still use unimproved drinking water sources, including unprotected wells and springs and surface water. The majority of them live in two developing regions: Sub-Saharan Africa representing nearly half of all people and Southern Asia representing one fifth of all people (WHO and UNICEF, 2015). Rural populations are particularly disadvantaged, accounting for $93 \%$ of the people using surface water.

In the populations of Sub-Saharan Africa, the proportion of people using unimproved drinking water was $52 \%$ in 1990 and $32 \%$ in 2015. The proportions of surface waters were $26 \%$ in 1990 and 10\% in 2015 (for example in Benin the proportions of people using unimproved drinking water were $43 \%$ in 1990 and $22 \%$ in 2015 . The proportions of surface waters were $22 \%$ in 1990 and $2 \%$ in 2015) (WHO and UNICEF, 2015). In the populations of Western Asia, the proportion of people using unimproved drinking water was $15 \%$ in 1990 and $5 \%$ in 2015 . The proportions of surface waters were $3 \%$ in 1990 and 1\% in 2015 (for example in 
Oman the proportions of people using unimproved drinking water were $21 \%$ in 1990 and $7 \%$ in 2015 . The proportion of surface waters was $6 \%$ in 1990 and no data was available for 2015) (WHO and UNICEF, 2015).

\subsubsection{In sewage, sludge, ground water and soil}

In schistosomes, there is no maturation of eggs in water, soil or sludge. The eggs laid by the female are embryonic (already mature) and after leaving the human body (in urine or in feces), only contact with freshwater is likely to cause the miracidium hatching. Once the miracidium out of the eggshell, it has less than 12 hours to find the specific snail intermediate host to penetrate, otherwise it is definitely condamned (Moné and Fournier, 1994). The miracidium is covered with ciliate plates that allow it to swim in the water and any other muddy or viscous medium would dramatically displace its movement. In addition, snail intermediate host of the genus Biomphalaria and Bulinus live and survive only in fairly clean waters containing the vegetation on which they feed. Unlike other helminths such as nematodes, it is therefore impossible for eggs of schistosomes to survive in soil or sludge or in wastewater or groundwater or sewage.

\subsubsection{In seawater, fish and shellfish}

Human schistosomes depend on their snail intermediate hosts that are freshwater snails that cannot survive in seawater. Neither fish nor shellfish are implicated in the life cycle of schistosomes.

\subsection{Persistence and Survival Data}

\subsubsection{Persistence of eggs}

Numerous environmental factors modulate egg hatching (Bair and Etges, 1973; Xu and Dresden, 1990). For temperature, the optimum is between $22^{\circ} \mathrm{C}$ and $28^{\circ} \mathrm{C}$ and hatching is inhibited at $4^{\circ} \mathrm{C}$. For lighting, light has a stimulatory effect on egg hatching in the first hours after water contact. However, eggs continue to hatch in darkness. For $\mathrm{pH}$, acidic $\mathrm{pH}$ inhibits $S$. japonicum (Ingalls et al., 1949) but not $S$. mansoni (Maldonado et al., 1950) egg hatching. For salinity, saline solution $(>0.6 \%)$ inhibits the egg hatching whatever the salt. Osmotic pressure, due to the diffusion of water into the egg, appears to be the most important factor in egg hatching. For oxygen, egg hatching is inhibited at low concentration of dissolved oxygen (Kawata and Kruse, 1966).

\subsubsection{Persistence of miracidia}

Free miracidia do not feed, they live on stored energy and their survival is determined by the percentage of living miracidia over time. To measure the miracidial survival, a group of miracidia is placed in spring water and the counting is done every 30 minutes under the binocular microscope. The experiment is repeated several times. The water is renewed each two hours. The half-life corresponds to the time at which $50 \%$ of the miracidial population die.
In $S$. mansoni, the half-life of miracidia was 8 hours and only $10 \%$ of the miracidia survived after 10 hours (Moné and Fournier, 1994). The count of miracidia was done by two observers and any miracidium that lies at the bottom of the container without moving is declared dead and removed from the container. The half-life of miracidia depends on the solution in which they are placed. In $S$. mansoni, the half-life of miracidia placed in snail conditionned water (spring water where the snail intermediate hosts have remained few hours) is $6.5 \mathrm{~h}$ and at the end of $10 \mathrm{~h}$, no living miracidium remains (Moné and Fournier, 1994). The decrease in survival is related to the intense activity spent by miracidia to find the snail when placed in snail conditionned water. The lifespan of miracidia is around 12 hours (Anderson et al., 1982; Liberatos, 1987).

\subsubsection{Persistence of cercariae}

Cercariae do not feed, they live on stored energy and their survival is determined by the percentage of living cercariae over time. To measure cercarial survival, a group of cercariae is placed in spring water and the counting is done every two hours under the binocular microscope. The experiment is repeated several times. The half-life corresponds to the time at which $50 \%$ of the cercarial population die. In $S$. mansoni, the half-life of cercariae was 21 hours for males and 23 hours for females (Liberatos, 1987). The lifespan of cercariae varies according to the authors: around 24 hours (Schreiber and Schubert, 1949), 39 hours (Liberatos, 1987), 48 hours (Whitfield et al., 2003) and 72 hours (Kuntz and Stirewalt, 1946).

\subsubsection{Persistence of infected snails}

The half life of Bulinus snails infected with $S$. haematobium was around 14 weeks (Chu et al., 1966). The half life of Biomphalaria snails infected with $S$. mansoni was around 14 weeks (Liberatos, 1987). Regarding Oncomelania snails infected with $S$. japonicum, $41 \%$ were surviving after 10 weeks post-infection (Pesigan et al., 1958).

\subsection{Reductions (in Number and Viability) by Sanitation Management}

\subsection{Egg Schistosomes and Wastewater}

Except cases of ectopic localisation, in schistosomes, the eggs are excreted predominantly in urine in only one species, S. haematobium, whereas the eggs of the other species (S. japonicum, S. mekongi, S. mansoni, S. intercalatum and $S$. guineensis) are excreted in faeces. Schistosomes are transmitted through open defecation, urination or perianal cleaning close to or in water body where the miracidia can hatch and find the appropriate snail host to complete their life cycle. In light of this, Water, Sanitation and Hygiene measures (WASH) remain critically important to schistosome global public health control measures (Brown et al., 2013). Lack of sanitation affects 2.4 billion people around the world with $80 \%$ of impacted individuals living in Asia, 13\% living in Africa and 5\% living in Latin America and the Caribbean (WHO and UNICEF, 
2015). Global burden of disease suggests that lack of access to safe water, sanitation and hygiene is the third most significant risk factor for poor health in developing countries. In addition, the median expected reduction in schistosomiasis morbidity and mortality from improved water supply and sanitation has been estimated to be as high as 70\% (Evans et al., 2004). However, the potential health benefit of piped water supply to each house is limited if no way to remove wastewater exists. For example, unsafe disposal of latrine effluent was implicated in schistosomiasis transmission in two Nile Delta villages in Egypt (Watts, 2004).

An overview of technologies for management of excreta is presented in WHO Guidelines for the safe use of wastewater, excreta, and greywater (WHO, 2006b); it is based on the collection, treatment and use options of excreta. The one-site sanitation options serve for a single home or for small clusters of homes; they consist in the traditional septic tanks and soil infiltration systems and the more recent systems such as pit toilets, composting/dehydration toilets, urine diversion toilets and water-saving toilets. Vacuum and low-flush gravity toilets may be used for urban situations. The collected faecal material from any of those systems may contain a high number of pathogens if it has been stored for a short period of time (one or two weeks); then a secondary treatment of the faecal sludges is needed to reach a tolerable risk threshold. Constructed wetlands and waste-stabilization ponds may be used for these sludges and for greywater treatment. Norms and practices with respect to excretion vary according to the societies (WHO, 2006b).

\subsection{Urine and Faeces as Fertilizers}

A WHO guideline provides information on the safe use of wastewater, excreta and greywater as resources for enhancing crop productivity (WHO, 2006b). It has been produced according to the principles of the Stockholm Framework which combines risk assessment and risk management to control water-related infectious diseases. One of the risks is the exposure to pathogens. This risk is carried out either directly via epidemiological studies or indirectly via a tool called quantitative microbial risk assessment (QMRA). In this last case, the risk is a calculation integrating the pathogen identification and characterization and the exposure assessment. According to WHO (WHO, 2006b), the use of treated excreta should not pose a risk but the use of untreated faecal material could be problematic, especially if the untreated faecal material may come into contact with freshwater places where the intermediate snail hosts are present. In the same way, using urine in arable lands, which was stored for some days, should not pose a risk unlike fresh urine. Pathogen inactivation is critical for controlling helminth transmission; treatment of urine and faeces is thus necessary.

Human excreta may provide nitrogen, phosphorus and potassium which are the major nutrients for plants. Urine is used as fertilizer since it is rich in nitrogen; faeces also may be used as fertilizer, especially dried (desiccated, incinerated, composted) fecal material, since the concentration of phosphorus and potassium are higher in faeces compared to urine (WHO, 2006b). The treatment of the faeces may consist of alkaline treatment ( $\mathrm{pH}$ more than 9 during more than 6 months), incineration or composting (temperature more than $50^{\circ} \mathrm{C}$ for more than one week) (WHO, 2006b).

Many people use untreated or partially treated human waste as an agricultural fertilizer, often called "night soil." The association between $S$. japonicum infections and night soil was studied in 36 villages in China in 2007 and 2010 in an area where schistosomiasis reemerged and persisted despite an aggressive disease control program (Carlton et al., 2015). The authors hypothesized that night soil use may facilitate the spread of $S$. japonicum schistosomiasis, as some eggs can survive in the environment for weeks. They found that night soil use was correlated with schistosome infection in 2007, even in households with improved sanitation, like anaerobic biogas digesters, the predominant improved sanitation system in the region; their explanation is that the low temperatures in winter or spring can impact biogas digestion and thus enhance schistosome egg survival. They also found that cessation of night soil use would lead to a $49 \%$ reduction in infection prevalence in 2007 but not these findings did not hold true in 2010. One of their hypotheses to explain this result is that in 2010 different sources of schistosome eggs such as from bovine fecal waste were added.

\subsection{Comprehensive Approaches for Examining Relationship Between Water, Sanitation and Schistosomiasis}

A systematic review and a meta-analysis were performed using 44 relevant studies containing 90 datasets on the relationship between water, sanitation and schistosomiasis (Grimes et al., 2014). These authors showed that increasing access to safe water and adequate sanitation are important measures to reduce the odds of schistosome infection. However, they recommended that future more rigorous studies comparing WASH (Water, Sanitation and Hygiene) with schistosome infection should be done.

A total of 23 environmental inducers were used in the district of Campinas in Sao Paulo State in Brazil in order to provide risk maps pinpointing schistosomiasis "hot spots" and that should be useful as guides for public preventive interventions (Anaruma Filho et al., 2010). These authors showed that (i) sewage with disposal represented only onethird of the area, (ii) sewage without disposal represented more than $10 \%$ and was correlated to a high risk because of the poorly structured septic tanks and (iii) sewage discharge into the river represented $1.3 \%$ and was found to be correlated to very high risk of being infected by $S$. mansoni in the surrounding areas and downstream.

Multiple linear regressions were applied with a schistosomiasis index from 1590 localities in Brazil as dependent variable and 93 quantitative variables (28 environmental and 65 socio-economical variables) and one qualitative variable (presence or absence of Biomphalaria glabrata, the snail vector for schistosomiasis) as explanatory variables (Guimaraes et al., 2013). Among the 
quantitative variables were the sanitary conditions (percentage of domiciles with bathroom connected to rivers or lakes, connected to a ditch, to rudimentary sewage, to septic sewage, to a general net, to other sewerage type, with bathroom or sanitarium and without bathroom or sanitarium) and water quality and access (percentage of domicile with access to general net of water supply, access to the water through wells or springheads and with other access forms to the water). In all the models that were generated, sanitation was part of the four most important parameters, together with the presence of $B$. glabrata, temperature and the vegetation index, that were found to be positively correlated with the schistosomiasis index.

Mathematical models were used to quantify environmental impacts on $S$. japonicum transmission in China (Liang et al., 2007). Among the factors that were analyzed, sanitation practices played a central role. Furthermore, the results highlighted the inadequacy of the niclosamide-Praziquantel strategy alone to achieve interruption of transmission (Liang et al., 2007). Niclosamide was used as a molluscicide and Praziquantel as an antihelminthic for humans. The authors showed that, in some places, treatment of human waste in household biogas digestors resulted in more than a $2 \log _{10}$ reduction of schistosome egg concentration by biochemical inactivation and separately another $1 \log _{10}$ reduction by sedimentation (Liang et al., 2007).

A comprehensive approach was conducted in four villages in which S. japonicum is endemic around Poyang Lake (China) and where annual synchronous chemotherapy is routinely used (Wang et al., 2009). From 2005 to 2007 new interventions included removing cattle from snailinfested grasslands, providing farmers with mechanized farm equipment, improving sanitation by supplying tap water and building lavatories and latrines, providing boats with fecal-matter containers, and implementing an intensive health-education program. The human rate of infection decreased from $10 \%$ to less than $1.0 \%$ in the intervention villages $(p$

\section{4 $\log _{10}$ Reduction of Viable Eggs}

The $\log 10$ unit pathogen reduction level is measured by the percentage of viable eggs out of the total egg population (WHO, 2006b). The helminth egg $\log _{10}$ reduction (mainly based on Ascaris eggs in the literature and not on schistosome eggs) depends on the treatment: it goes from $0.5 \log _{10}$ in anaerobic (mesophilic) treatment and in pretreatment in drying beds for dewatering to $3 \log _{10}$ using faecal sludge settling ponds, $\mathrm{pH}$ elevation more than 12 and thermophilic treatment; composting and constructed wetlands being in the middle, around $2 \log _{10}$ reduction.

In an overview of existing policy making and guidelines and research, schistosome eggs were found to potentially be eliminated in composting toilets after three months retention time and killed in one hour at $50^{\circ} \mathrm{C}$ in a thermophilic composting (Gajurel and Wendland, 2007).

The WHO microbiological quality guideline is zero viable human trematode eggs per liter of treated wastewater (WHO, 1989). Helminth eggs are easily removed during water treatment. Performance for helminth removal after primary treatment (gravity and sedimentation) ranges from $0.4 \log _{10}$ to $2 \log _{10}$. Because the schistosome egg have a large size (60 x $150 \mu \mathrm{m}$ in average) compare to other helminths their free falling velocity is very high $\left(5.24 \mathrm{~m} / \mathrm{h}\right.$ at $5^{\circ} \mathrm{C}$ and $7.87 \mathrm{~m} / \mathrm{h}$ at $20^{\circ} \mathrm{C}$ ) (Duncan and Horan, 2003). Systems involving primary and secondary sewage treatment without chlorination were highly successful in removing $S$. mansoni eggs (2.3 $\log _{10}$ of the eggs are removed) (Rowan, 1964). The efficiency of removal rate of schistosome from contaminated water is facilitated by the fact that eggs hatch in experimental waste-water tanks (Jones and Brady, 1947; Jones and Hummel, 1947; Jones et al., 1947). Subsequently, molluscs exposed to purified sewage effluent were not at risk of being infected (Rowan, 1964).

As emphasized by WHO and other scientists, the reduction of schistosomiasis transmission worldwide is mainly based both on the access to drinking water and on the building or improvement of the wastewater sanitation. These measures must, of course, be accompanied by an effort to educate the population in order to avoid behaviors which may initiate or aggravate schistosomiasis transmission and by sustained control measures of the intermediate snail host in breeding waterbodies. 


\section{References}

-Nations, U. (2015). The Millenium Development Goals Report 2015.

/UNICEF, W.H.O. (2014). Progress on Sanitation and Drinking-water, 2014 Update. World Health Organization. Geneva.

Abbasi, I., King, C.H., Muchiri, E.M. and Hamburger, J. (2010). Detection of Schistosoma mansoni and Schistosoma haematobium DNA by loop-mediated isothermal amplification: identification of infected snails from early prepatency. The American Journal of Tropical Medicine and Hygiene. 83, pp. 427-32.

Abel, L., Demenais, F., Prata, A., Souza, A.E. and Dessein, A. (1991). Evidence for the segregation of a major gene in human susceptibility/resistance to infection by Schistosoma mansoni. American Journal of Human Genetics. 48, pp. 959-70.

Adema, C.M., Hertel, L.A., Miller, R.D. and Loker, E.S. (1997). A family of fibrinogen-related proteins that precipitates parasite-derived molecules is produced by an invertebrate after infection. Proceedings of the National Academy of Sciences of the United States of America. 94, pp. 8691-6.

Ahmed, A.A., Babiker, A., Eltash, L.A. and Shiff, C. (2002). Development of a modified baited trap for detection of schistosome cercariae using natural oils rich in polyunsaturated fatty acids in Sudan. Acta Tropica. 82, pp. 363-8.

Allan, F., Dunn, A.M., Emery, A.M., Stothard, J.R., Johnston, D.A., Kane, R.A. et al. (2013). Use of sentinel snails for the detection of Schistosoma haematobium transmission on Zanzibar and observations on transmission patterns. Acta Tropica. 128 , pp. 234-40.

Anderson, R.M., Mercer, J.G., Wilson, R.A. and Carter, N.P. (1982). Transmission of Schistosoma mansoni from man to snail: experimental studies of miracidial survival and infectivity in relation to larval age, water temperature, host size and host age. Parasitology. 85 (Pt 2), pp. 339-60.

Arafa, M.A. and Massoud, M.M. (1990). Natural Schistosoma mansoni infection in Arvicanthis niloticus in Ismailia, Egypt. Journal of the Egyptian Society of Parasitology. 20, pp. 775-8.

Bair, R.D. and Etges, F.J. (1973). Schistosoma mansoni: factors affecting hatching of eggs. Experimental Parasitology. 33, pp. 155-67.

Barbosa, F.S. (1972). Natural infection with Schistosoma mansoni in small mammals trapped in the course of a schistosomiasis control project in Brazil. Journal of Parasitology. 58, pp. 405-7.

Bass, D., Stentiford, G.D., Littlewood, D.T. and Hartikainen, H. (2015). Diverse Applications of Environmental DNA Methods in Parasitology. Trends in Parasitology. 31, pp. 499-513.

Beniguel, L., Diallo, T.O., Remoue, F., Williams, D.L., Cognasse, F., Charrier-Mze, N. et al. (2003). Differential production in vitro of antigen specific IgG1, IgG3 and IgA: a study in Schistosoma haematobium infected individuals. Parasite Immunology. 25, pp. 39-44.

Berry, A., Moné, H., Iriart, X., Mouahid, G., Aboo, O., Boissier, J. et al. (2014). Schistosomiasis Haematobium, Corsica, France. Emerging Infectious Diseases. 20, pp. 1595-1597.

Bohmann, K., Evans, A., Gilbert, M.T., Carvalho, G.R., Creer, S., Knapp, M. et al. (2014). Environmental DNA for wildlife biology and biodiversity monitoring. Trends in Ecology and Evolution. 29, pp. 358-67.

Boissier, J., Grech-Angelini, S., Webster, B.L., Allienne, J.F., Huyse, T., Mas-Coma, S. et al. (2016). Outbreak of urogenital schistosomiasis in Corsica (France): an epidemiological case study. The Lancet. Infectious Diseases.

Boissier, J., Moné, H., Mitta, G., Bargues, M.D., Molyneux, D. and Mas-Coma, S. (2015). Schistosomiasis reaches Europe. The Lancet. Infectious Diseases. 15, pp. 757-8.

Brémond, P., Sellin, B., Sellin, E., Nameoua, B., Labbo, R., Théron, A. et al. (1993). [Arguments for the modification of the 
genome (introgression) of the human parasite Schistosoma haematobium by genes from S. bovis, in Niger]. Comptes Rendus de l'Académie des Sciences - Series III. 316, pp. 667-70.

Brooker, S. (2007). Spatial epidemiology of human schistosomiasis in Africa: risk models, transmission dynamics and control. Transactions of the Royal Society of Tropical Medicine and Hygiene. 101, pp. 1-8.

Brown, D. (1994). Freshwater snails of Africa and their medical importance. Second Edition Taylor and Francis.

Brown, J., Cairncross, S. and Ensink, J.H. (2013). Water, sanitation, hygiene and enteric infections in children. Archives of Disease in Childhood. 98, pp. 629-34.

Burchard, G.D. and Kern, P. (1985). Probable hybridization between S. intercalatum and S. haematobium in western Gabun. Tropical and geographical medicine. 37, pp. 119-23.

Cao, Z.G., Zhao, Y.E., A. Willingham, L. and Wang, T.P. (2016). Towards the Elimination of Schistosomiasis japonica through Control of the Disease in Domestic Animals in The People's Republic of China: A Tale of over 60Years. Advances in Parasitology. 92, pp. 269-306.

Carlton, E.J., Liu, Y., Zhong, B., Hubbard, A. and Spear, R.C. (2015). Associations between schistosomiasis and the use of human waste as an agricultural fertilizer in China. PLOS Neglected Tropical Diseases. 9, pp. e0003444.

Cheng, W., Curti, E., Rezende, W.C., Kwityn, C., Zhan, B., Gillespie, P. et al. (2013). Biophysical and formulation studies of the Schistosoma mansoni TSP-2 extracellular domain recombinant protein, a lead vaccine candidate antigen for intestinal schistosomiasis. Human Vaccines and Immunotherapeutics. 9, pp. 2351-61.

Chen, M.G. (1993). Schistosoma japonicum and S. japonicum-like infections: epidemiology, clinical and pathological aspects. Human Schistosomiasis (ed. Jordan, P., Webbe, G. \&amp; Sturrock, R.F.), CAB international.

Chitsulo, L., Engels, D., Montresor, A. and Savioli, L. (2000). The global status of schistosomiasis and its control. Acta Tropica. 77, pp. 41-51.

Chu, K.Y., Massoud, J. and Sabbaghian, H. (1966). Host-parasite relationship of Bulinus truncatus and Schistosoma haematobium in Iran. 1. Effect of the age of B. truncatus on the development of S. haematobium. Bulletin of the World Health Organization. 34, pp. 113-9.

Colley, D.G., Bustinduy, A.L., Secor, W.E. and King, C.H. (2014). Human schistosomiasis. Lancet. 383, pp. 2253-64.

Colley, D.G. and Secor, W.E. (2014). Immunology of human schistosomiasis. Parasite Immunology. 36, pp. 347-57.

Combes, C., Fournier, A., Moné, H. and Théron, A. (1994). Behaviours in trematode cercariae that enhance parasite transmission: patterns and processes. Parasitology. 109 Suppl, pp. S3-13.

Coustau, C., Gourbal, B., Duval, D., Yoshino, T.P., Adema, C.M. and Mitta, G. (2015). Advances in gastropod immunity from the study of the interaction between the snail Biomphalaria glabrata and its parasites: A review of research progress over the last decade. Fish and Shellfish Immunology. 46, pp. 5-16.

D'Andrea, P.S., Maroja, L.S., Gentile, R., Cerqueira, R., A. Junior, M. and Rey, L. (2000). The parasitism of Schistosoma mansoni (Digenea-Trematoda) in a naturally infected population of water rats, Nectomys squamipes (RodentiaSigmodontinae) in Brazil. Parasitology. 120 ( Pt 6), pp. 573-82.

Da'dara, A.A., Li, Y.S., Xiong, T., Zhou, J., Williams, G.M., McManus, D.P. et al. (2008). DNA-based vaccines protect against zoonotic schistosomiasis in water buffalo. Vaccine. 26, pp. 3617-25.

Dheilly, N.M., Duval, D., Mouahid, G., Emans, R., Allienne, J.F., Galinier, R. et al. (2015). A family of variable immunoglobulin and lectin domain containing molecules in the snail Biomphalaria glabrata. Developmental and Comparative Immunology. 48, pp. 234-43.

Dias, L.C.S., Avilapires, F.D. and Pinto, A.C.M. (1978). Parasitological and ecological aspects of schistosomiasis mansoni in 
Valley of Paraiba do Sul River (Sao-Paulo-State, Brazil). 1. Natural infection of small mammals with Schistosoma mansoni. Transactions of the Royal Society of Tropical Medicine and Hygiene. 72, pp. 496-500.

Duncan, M. and Horan, N.J. (2003). Handbook of Water and Wastewater Microbiology. Academic Press. pp. 832 p.

Dunne, D.W. and Pearce, E.J. (1999). Immunology of hepatosplenic schistosomiasis mansoni: a human perspective. Microbes and Infection. 1, pp. 553-60.

Duplantier, J.M. and Sene, M. (2000). Rodents as reservoir hosts in the transmission of Schistosoma mansoni in RichardToll, Senegal, West Africa. Journal of Helminthology. 74, pp. 129-35.

Evans, B.E., Haller, L. and Hutton, G. (2004). Closing the sanitation gap: the case for better public funding of sanitation and hygiene. OECD. Paris.

Farooq, M., Nielsen, J., Samaan, S.A., Mallah, M.B. and Allam, A.A. (1966). The epidemiology of Schistosoma haematobium and $S$. mansoni infections in the Egypt-49 project area. 3. Prevalence of bilharziasis in relation to certain environmental factors. Bulletin of the World Health Organization. 35, pp. 319-30.

Favre, T.C., Bogea, T., Rotenberg, L., Silva, H.S. and Pieri, O.S. (1995). Cercarial emergence of Schistosoma mansoni from Biomphalaria glabrata and Biomphalaria straminea. Memorias do Instituto Oswaldo Cruz Rio de Janeiro. 90, pp. 565-567.

Figueiredo, J.C., Richter, J., Borja, N., Balaca, A., Costa, S., Belo, S. et al. (2015). Prostate adenocarcinoma associated with prostatic infection due to Schistosoma haematobium. Case report and systematic review. Parasitology Research. 114, pp. 351-8.

F. Filho, A., Sant'Ana, J.M., Santos, R.F. dos and Castagna, C.L. (2010). Environmental inducers of schistosomiasis mansoni in Campinas, Brazil. Geospat Health. 5, pp. 79-91.

Frandsen, F., Monrad, J., Christensen, N.O. and Nansen, P. (1978). Sheep as a potential reservoir host for Schistosoma intercalatum. Journal of Parasitology. 64, pp. 1136.

Günther, S. (1979). Rats: important natural reservoir hosts of Bilharzia in Egypt? (Preliminary report). The Medical Journal of Cairo University. 47, pp. 87-89.

Gajurel, D.R. and Wendland, C. (2007). Ecological sanitation and associated hygienic risk. Human in Europe for a Common Future.

Gentile, R., Costa-Neto, S.F., Goncalves, M.M.L., Bonecker, S.T., Fernandes, F.A., Garcia, J.S. et al. (2006). An ecological field study of the water-rat Nectomys squamipes as a wild reservoir indicator of Schistosoma mansoni transmission in an endemic area. Memorias Do Instituto Oswaldo Cruz. 101, pp. 111-117.

Ghandour, A.M., Al-Robai, A. and M. Gohary, E. (1986). An ecological study on some aspects of schistosomiasis in the MidWestern region of Saudi Arabia. The Arab Gulf Journal of Scientific Research. 4, pp. 203-219.

Gobert, G.N., Chai, M. and McManus, D.P. (2007). Biology of the schistosome lung-stage schistosomulum. Parasitology. 134, pp. 453-60.

Gomes, E.C., Leal-Neto, O.B., de Oliveira, F.J., Jr., J.V.Campos, Souza-Santos, R. and Barbosa, C.S. (2014). Risk analysis for occurrences of schistosomiasis in the coastal area of Porto de Galinhas, Pernambuco, Brazil. BMC Infectious Diseases. 14, pp. 101.

Gray, D.J., Ross, A.G., Li, Y.S. and McManus, D.P. (2011). Diagnosis and management of schistosomiasis. The BMJ. 342, pp. d2651.

Grimes, J.E., Croll, D., Harrison, W.E., Utzinger, J., Freeman, M.C. and Templeton, M.R. (2015). The roles of water, sanitation and hygiene in reducing schistosomiasis: a review. Parasites and Vectors. 8, pp. 156.

Grimes, J.E., Croll, D., Harrison, W.E., Utzinger, J., Freeman, M.C. and Templeton, M.R. (2014). The relationship between 
water, sanitation and schistosomiasis: a systematic review and meta-analysis. PLOS Neglected Tropical Diseases. 8, pp. e3296.

Gryseels, B., Polman, K., Clerinx, J. and Kestens, L. (2006). Human schistosomiasis. Lancet. 368, pp. 1106-18.

Guimaraes, R.J.P.S., Freitas, C.C., Dutra, L.V., Oliveira, G. and Carvalho, O.S. (2013). Multiple regression for the Schistosomiasis positivity index estimates in the Minas Gerais State-Brazil at small communities and cities levels. Parasitic Diseases-Schistosomiasis - InTech.

Hamburger, J., He, N., Abbasi, I., Ramzy, R.M., Jourdane, J. and Ruppel, A. (2001). Polymerase chain reaction assay based on a highly repeated sequence of Schistosoma haematobium: a potential tool for monitoring schistosome-infested water. The American Journal of Tropical Medicine and Hygiene. 65, pp. 907-11.

Hamburger, J., Turetski, T., Kapeller, I. and Deresiewicz, R. (1991). Highly repeated short DNA sequences in the genome of Schistosoma mansoni recognized by a species-specific probe. Molecular and Biochemical Parasitology. 44, pp. 73-80.

Holtfreter, M.C., Moné, H., Muller-Stover, I., Mouahid, G. and Richter, J. (2014). Schistosoma haematobium infections acquired in Corsica, France, August 2013. Eurosurveillance. 19,.

Hotez, P.J., Alvarado, M., Basanez, M.G., Bolliger, I., Bourne, R., Boussinesq, M. et al. (2014). The global burden of disease study 2010: interpretation and implications for the neglected tropical diseases. PLOS Neglected Tropical Diseases. 8, pp. e2865.

Hung, Y.W. and Remais, J. (2008). Quantitative detection of Schistosoma japonicum cercariae in water by real-time PCR. PLOS Neglected Tropical Diseases. 2, pp. e337.

Huver, J.R., Koprivnikar, J., Johnson, P.T. and Whyard, S. (2015). Development and application of an eDNA method to detect and quantify a pathogenic parasite in aquatic ecosystems. Ecological Applications. 25, pp. 991-1002.

Huyse, T., Van den Broeck, F., Hellemans, B., Volckaert, F.A. and Polman, K. (2013). Hybridisation between the two major African schistosome species of humans. International Journal of Parasitology. 43, pp. 687-9.

Huyse, T., Webster, B.L., Geldof, S., Stothard, J.R., Diaw, O.T., Polman, K. et al. (2009). Bidirectional introgressive hybridization between a cattle and human schistosome species. PLoS Pathogens. 5, pp. e1000571.

Ibikounlé, M., Mouahid, G., R. Nguéma, M., Sakiti, N.G., Kindé-Gasard, D., Massougbodji, A. et al. (2012). Life-history traits indicate local adaptation of the schistosome parasite, Schistosoma mansoni, to its snail host, Biomphalaria pfeifferi. Experimental Parasitology. 132, pp. 501-7.

Ibikounlé, M., Mouahid, G., R. Nguéma, M., Sakiti, N., Massougbodji, A. and Moné, H. (2013). Snail intermediate host/Schistosoma haematobium relationships from three transmission sites in Benin (West Africa). Parasitology Research. 112, pp. 227-33.

Imai, K., Koibuchi, T., Kumagai, T., Maeda, T., Osada, Y., Ohta, N. et al. (2011). Cerebral schistosomiasis due to Schistosoma haematobium confirmed by PCR analysis of brain specimen. Journal of Clinical Microbiology. 49, pp. 3703-6.

Imbert-Establet, D. (1982). Infestation naturelle des rats sauvages par Schistosoma mansoni en Guadeloupe : données quantitatives sur le développement et la fertilité du parasite. Annales de Parasitologie Humaine et Comparée. 57, pp. 573-585.

Imbert-Establet, D., Moné, H., Tchuenté, L.A.Tchuem and Jourdane, J. (1997). Permissiveness of two African wild rodents, Mastomys huberti and Arvicanthis niloticus, to Schistosoma intercalatum: epidemiological consequences. Parasitology Research. 83, pp. 569-73.

Ingalls, Jr., J.W.,,. and,. (1949). The molluscan intermediate host and schistosomiasis japonica; observations on the conditions governing the hatching of the eggs of Schistosoma japonicum. Journal of Parasitology. 35, pp. 147-51.

Isnard, A. and Chevillard, C. (2008). Recent advances in the characterization of genetic factors involved in human 
susceptibility to infection by schistosomiasis. Curr Genomics. 9, pp. 290-300.

Jones, M.F. and Brady, F.J. (1947). Effects of water treatment processes on schistosome cercariae. Bulletin of National Institute of Health Sciences. 2, pp. 109-30.

Jones, M.F. and Hummel, M.S. (1947). The effect of chlorine and chloramine on schistosome ova and miracidia. Bulletin of National Institute of Health Sciences. 2, pp. 173-9.

Jones, M.F. and Newton, W.L. (1947). The effects of sewage treatment processes on the ova and miracidia of Schistosoma japonicum. Bulletin of National Institute of Health Sciences. 2, pp. 137-72.

Jourdane, J. and Théron, A. (1987). Larval development: eggs to cercariae. The biology of schistosomes. From genes to latrines. (Rollinson, D. and Simpson, A.J.G., ed.). Academic Press. London. pp. 83-113.

Kabatereine, N.B., Vennervald, B.J., Ouma, J.H., Kemijumbi, J., Butterworth, A.E., Dunne, D.W. et al. (1999). Adult resistance to schistosomiasis mansoni: age-dependence of reinfection remains constant in communities with diverse exposure patterns. Parasitology. 118 ( Pt 1), pp. 101-5.

Karoum, K.O. and Amin, M.A. (1985). Domestic and wild animals naturally infected with Schistosoma mansoni in the Gezira Irrigated Scheme, Sudan. Journal of Tropical Medicine and Hygiene. 88, pp. 83-89.

Kawata, K. and Kruse, C.W. (1966). The effect of sewage stabilization ponds on the eggs and miracidia of Schistosoma mansoni. The American Journal of Tropical Medicine and Hygiene. 15, pp. 896-901.

King, C.H. (2010). Parasites and poverty: the case of schistosomiasis. Acta Tropica. 113, pp. 95-104.

King, C.H., Blanton, R.E., Muchiri, E.M., Ouma, J.H., Kariuki, H.C., Mungai, P. et al. (2004). Low heritable component of risk for infection intensity and infection-associated disease in urinary schistosomiasis among Wadigo village populations in Coast Province, Kenya. The American Journal of Tropical Medicine and Hygiene. 70, pp. 57-62.

King, C.H., Dickman, K. and Tisch, D.J. (2005). Reassessment of the cost of chronic helmintic infection: a meta-analysis of disability-related outcomes in endemic schistosomiasis. Lancet. 365, pp. 1561-9.

Kjetland, E.F., Leutscher, P.D. and Ndhlovu, P.D. (2012). A review of female genital schistosomiasis. Trends in Parasitology. 28, pp. 58-65.

Kloos, H., Correa-Oliveira, R., Reis, D.C.dos, Rodrigues, E.W., Monteiro, L.A. and Gazzinelli, A. (2010). The role of population movement in the epidemiology and control of schistosomiasis in Brazil: a preliminary typology of population movement. Memorias do Instituto Oswaldo Cruz. 105, pp. 578-86.

Kloos, H., Gardiner, C.H., Selim, A. and Higashi, G.I. (1982). Laboratory and field evaluation of a direct filtration technique for recovery of schistosome cercariae. The American Journal of Tropical Medicine and Hygiene. 31, pp. 122-7.

Kuntz, R.E. (1958). Schistosoma sp in shrews in Lower Egypt. Proceedings of the Helminthological Society of Washington. 25, pp. 37-40.

Kuntz, R.E. (1952). Natural infection of an Egyptian gerbil with Schistosoma mansoni. Proceedings of the Helminthological Society of Washington. 19, pp. 123-124.

Kuntz, R.E. and Stirewalt, M.A. (1946). Effects of DDT on cercariae of Schistosoma mansoni. Journal of Parasitology. 32, pp. 529-38.

Lawton, S.P., Hirai, H., Ironside, J.E., Johnston, D.A. and Rollinson, D. (2011). Genomes and geography: genomic insights into the evolution and phylogeography of the genus Schistosoma. Parasites and Vectors. 4, pp. 131.

Liang, S., Seto, E.Y., Remais, J.V., Zhong, B., Yang, C., Hubbard, A. et al. (2007). Environmental effects on parasitic disease transmission exemplified by schistosomiasis in western China. Proceedings of the National Academy of Sciences of the United States of America. 104, pp. 7110-5. 
Liberatos, J.D. (1987). Schistosoma mansoni: male-biased sex ratios in snails and mice. Experimental Parasitology. 64, pp. $165-77$.

Long, X., Chen, Q., Zhao, J., Rafaels, N., Mathias, P., Liang, H. et al. (2015). An IL-13 promoter polymorphism associated with liver fibrosis in patients with Schistosoma japonicum. PLoS One. 10, pp. e0135360.

Lozano, R., Naghavi, M., Foreman, K., Lim, S., Shibuya, K., Aboyans, V. et al. (2012). Global and regional mortality from 235 causes of death for 20 age groups in 1990 and 2010: a systematic analysis for the Global Burden of Disease Study 2010. Lancet. 380, pp. 2095-128.

Maldonado, J.F., J. Matienzo, A. and F. Herrera, V. (1950). Biological studies on the miracidium of Schistosoma mansoni. III. The role of light and temperature in hatching. The Puerto Rico Journal of Public Health and Tropical Medicine. 25, pp. 359-66; Spanish transl 367-76.

Mandahl-Barth, G. (1957). Intermediate hosts of Schistosoma. African Biomphalaria and Bulinus: 2. Bulinus. Bulletin of the World Health Organization. 17, World Health Organization. pp. 1-65.

Mansour, N.S. (1978). Natural schistosome infection in rodents from endemic areas near Cairo and their possible role in the transmission of schistosomiasis. Proceedings of the International Conference on Schistosomiasis. pp. 157-164.

Mansour, N.S. (1973). Schistosoma mansoni and Schistosoma haematobium natural infection in the Nile-rat, Arvicanthis $\mathrm{n}$. niloticus from an endemic area in Egypt. Journal of the Egyptian Public Health Association. 48, pp. 94-100.

Marquet, S., Abel, L., Hillaire, D., Dessein, H., Kalil, J., Feingold, J. et al. (1996). Genetic localization of a locus controlling the intensity of infection by Schistosoma mansoni on chromosome 5q31-q33. Nature Genetics. 14, pp. 181-4.

Melman, S.D., Steinauer, M.L., Cunningham, C., Kubatko, L.S., Mwangi, I.N., Wynn, N.B. et al. (2009). Reduced susceptibility to praziquantel among naturally occurring Kenyan isolates of Schistosoma mansoni. PLOS Neglected Tropical Diseases. 3, pp. e504.

Merrifield, M., Hotez, P.J., Beaumier, C.M., Gillespie, P., Strych, U., Hayward, T. et al. (2016). Advancing a vaccine to prevent human schistosomiasis. Vaccine. 34, pp. 2988-91.

Mintsa-Nguéma, R. (2010). Interactions hôte-parasite dans le modèle Biomphalaria pfeifferi-Schistosoma mansoni du Dhofar (Oman): génétique des populations de l'hôte, traits d'histoire de vie et conséquences sur la transmission du parasite. Université de Perpignan Via Domitia, France and Université des Sciences de la Santé de Libreville, Gabon. Perpignan, Libreville. pp. 331 pages.

Mintsa-Nguéma, R., Moné, H., Ibikounlé, M., Mengue-Ngou-Milama, K., Kombila, M. and Mouahid, G. (2014). Cercarial emergence pattern of Schistosoma haematobium from Libreville, Gabon. Parasite. 21, pp. 3.

Mitta, G., Adema, C.M., Gourbal, B., Loker, E.S. and Théron, A. (2012). Compatibility polymorphism in snail/schistosome interactions: From field to theory to molecular mechanisms. Developmental and Comparative Immunology. 37, pp. 1-8.

Moné, H. (1991). Influence of non-target molluscs on the growth of Biomphalaria glabrata infected with Schistosoma mansoni: correlation between growth and cercarial production. Journal of Molluscan Studies. 57, pp. 1-10.

Moné, H. and Boissier, J. (2004). Sexual biology of schistosomes. Advances in Parasitology. 57, pp. 89-189.

Moné, H. and Fournier, A. (1994). Effects of snail-conditioned water on survival and host-searching behaviour of schistosome miracidia. Animal Behaviour. 48, pp. 1-8.

Moné, H., Holtfreter, M.C., Allienne, J.F., Mintsa-Nguéma, R., Ibikounlé, M., Boissier, J. et al. (2015). Introgressive hybridizations of Schistosoma haematobium by Schistosoma bovis at the origin of the first case report of schistosomiasis in Corsica (France, Europe). Parasitology Research. 114, pp. 4127-33.

Moné, H., Minguez, S., Ibikounlé, M., Allienne, J.F., Massougbodji, A. and Mouahid, G. (2014). Natural Interactions between S. haematobium and S. guineensis in the Republic of Benin. Scientific World Journal. 2012, pp. 793420. 
Moné, H., Mouahid, G. and Morand, S. (2000). The distribution of Schistosoma bovis Sonsino, 1876 in relation to intermediate host mollusc-parasite relationships. Advances in Parasitology. 44, pp. 99-138.

Moné, H., Théron, A. and Combes, C. (1986). Interaction between the Biomphalaria glabrata-Schistosoma mansoni hostparasite system and the non-target molluscs: influence on cercarial production. Journal of Parasitology. 72, pp. 410-6.

Mone, Y., Gourbal, B., Duval, D., Du Pasquier, L., Kieffer-Jaquinod, S. and Mitta, G. (2010). A large repertoire of parasite epitopes matched by a large repertoire of host immune receptors in an invertebrate host/parasite model. PLOS Neglected Tropical Diseases. 4,.

Morgan, J.A., DeJong, R.J., Lwambo, N.J., Mungai, B.N., Mkoji, G.M. and Loker, E.S. (2003). First report of a natural hybrid between Schistosoma mansoni and S. rodhaini. Journal of Parasitology. 89, pp. 416-8.

Mott, K.E. (1982). S. japonicum and S. japonicum-like infections. Schistosomiasis. Epidemiology, treatment and control. William Heinemann Medical Books. London. pp. 128-149.

Mouahid, A., Moné, H., Chaib, A. and Théron, A. (1991). Cercarial shedding patterns of Schistosoma bovis and $S$. haematobium from single and mixed infections of Bulinus truncatus. Journal of Helminthology. 65, pp. 8-14.

Mouahid, A. and Théron, A. (1986). Schistosoma bovis: patterns of cercarial emergence from snails of the genera Bulinus and Planorbarius. Experimental Parasitology. 62, pp. 389-93.

Mouahid, G., Idris, M.A., Verneau, O., Théron, A., Shaban, M.M. and Moné, H. (2012). A new chronotype of Schistosoma mansoni: adaptive significance. Tropical Medicice and International Health. 17, pp. 727-32.

Mouchet, F., Théron, A., Brémond, P., Sellin, E. and Sellin, B. (1992). Pattern of cercarial emergence of Schistosoma curassoni from Niger and comparison with three sympatric species of schistosomes. Journal of Parasitology. 78, pp. 61-3.

Muller-Graf, C.D., Collins, D.A., Packer, C. and Woolhouse, M.E. (1997). Schistosoma mansoni infection in a natural population of olive baboons (Papio cynocephalus anubis) in Gombe Stream National Park, Tanzania. Parasitology. 115 ( Pt 6), pp. 621-7.

Murray, C.J., Vos, T., Lozano, R., Naghavi, M., Flaxman, A.D., Michaud, C. et al. (2012). Disability-adjusted life years (DALYs) for 291 diseases and injuries in 21 regions, 1990-2010: a systematic analysis for the Global Burden of Disease Study 2010. Lancet. 380, pp. 2197-223.

N'Goran, E., Brémond, P., Sellin, E., Sellin, B. and Théron, A. (1997). Intraspecific diversity of Schistosoma haematobium in west Africa: chronobiology of cercarial emergence. Acta Tropica. 66, pp. 35-44.

Nicolas, M., Perez, J.M. and Carme, B. (2006). Intestinal parasitosis in French West Indies: endemic evolution from 1991 to 2003 in the University Hospital of Pointe-a-Pitre, Guadeloupe. Bulletin de la Société de Pathologie Exotique. 99, pp. 254-7.

Ouma, J.H. and Fenwick, A. (1991). Animal reservoirs of schistosomiasis. Parasitic helminths and zoonoses in Africa. 8, pp. 224-236.

Pagès, J.R. and Théron, A. (1990). Schistosoma intercalatum from Cameroon and Zaire: chronobiological differentiation of cercarial emergence. Journal of Parasitology. 76, pp. 743-5.

Pesigan, T.P., Hairston, N.G., Jauregui, J.J., Garcia, E.G., Santos, A.T., Santos, B.C. et al. (1958). Studies on Schistosoma japonicum infection in the Philippines. 2. The molluscan host. Bulletin of the World Health Organization. 18, pp. 481-578.

Pitchford, R.J. (1977). A check list of definitive hosts exhibiting evidence of the genus Schistosoma Weinland, 1858 acquired naturally in Africa and the Middle East. Journal of Helminthology. 51, pp. 229-52.

Pitchford, R.J. (1961). Observations on a possible hybrid between the two schistosomes S. haematobium and S. mattheei. Transactions of the Royal Society of Tropical Medicine and Hygiene. 55, pp. 44-51.

Pitchford, R.J. (1959). Natural schistosome infections in South African rodents. Transactions of the Royal Society of 
Tropical Medicine and Hygiene. 53, pp. 213.

Pitchford, R.J. and Du Toit, J.F. (1976). The shedding pattern of three little known African schistosomes under outdoor conditions. Annals of Tropical Medicine and Parasitology. 70, pp. 181-7.

Pitchford, R.J., Meyling, A.H., Meyling, J. and Du Toit, J.F. (1969). Cercarial shedding patterns of various schistosome species under outdoor conditions in the Transvaal. Annals of Tropical Medicine and Parasitology. 63, pp. 359-71.

Pitchford, R.J. and Visser, P.S. (1962). The role of naturally infected wild rodents in the epidemiology of schistosomiasis in the eastern Transvaal. Transactions of the Royal Society of Tropical Medicine and Hygiene. 56, pp. 126-35.

Portela, J., Boissier, J., Gourbal, B., Pradines, V., Colliere, V., Cosledan, F. et al. (2012). Antischistosomal activity of trioxaquines: in vivo efficacy and mechanism of action on Schistosoma mansoni. PLOS Neglected Tropical Diseases. 6, pp. e1474.

Prentice, M.A. (1984). A field-evolved differential filtration method for recovery of schistosome cercariae. Annals of Tropical Medicine and Parasitology. 78, pp. 117-27.

Raymond, K. and Probert, A.J. (1991). The daily cercarial emission rhythm of Schistosoma margrebowiei with particular reference to dark period stimuli. J Helminthol. 65, pp. 159-68.

Rey, L. (1993). Non-human vertebrate hosts of Schistosoma mansoni and schistosomiasis transmission in Brazil. Research and Reviews in Parasitology. 53, pp. 13-25.

Ricciardi, A. and Ndao, M. (2015). Still hope for schistosomiasis vaccine. Human Vaccines and Immunotherapeutics. 11, pp. 2504-8.

Riveau, G., Deplanque, D., Remoue, F., Schacht, A.M., Vodougnon, H., Capron, M. et al. (2012). Safety and immunogenicity of rSh28GST antigen in humans: phase 1 randomized clinical study of a vaccine candidate against urinary schistosomiasis. PLOS Neglected Tropical Diseases. 6, pp. e1704.

Roger, E., Mitta, G., Mone, Y., Bouchut, A., Rognon, A., Grunau, C. et al. (2008). Molecular determinants of compatibility polymorphism in the Biomphalaria glabrata/Schistosoma mansoni model: new candidates identified by a global comparative proteomics approach. Molecular and Biochemical Parasitology. 157, pp. 205-16.

Rollinson, D., Knopp, S., Levitz, S., Stothard, J.R., Tchuenté, L.A.Tchuem, Garba, A. et al. (2013). Time to set the agenda for schistosomiasis elimination. Acta Tropica. 128, pp. 423-40.

Rollinson, D. and Simpson, A.J.G. (1987). The biology of Schistosomes. From genes to latrines. Academic Press. London. pp. 446.

Rollinson, D. and Southgate, V.R. (1987). The genus Schistosoma: a taxonomic appraisal. The biology of schistosomes. From genes to latrines. (Rollinson, D. and Simpson, A.J.G., ed.). Academic Press. London. pp. 1-49.

Rollinson, D., Southgate, V.R., Vercruysse, J. and Moore, P.J. (1990). Observations on natural and experimental interactions between Schistosoma bovis and S. curassoni from West Africa. Acta Tropica. 47, pp. 101-14.

Ross, A.G., McManus, D.P., Farrar, J., Hunstman, R.J., Gray, D.J. and Li, Y.S. (2012). Neuroschistosomiasis. Journal of Neurology. 259, pp. 22-32.

Ross, A.G., Vickers, D., Olds, G.R., Shah, S.M. and McManus, D.P. (2007). Katayama syndrome. The Lancet. Infectious Diseases. 7, pp. 218-24.

Rowan, W.B. (1964). Sewage treatment and schistosome eggs. American Journal of Tropical Medicine and Hygiene. 13, pp. 572-576.

Sandt, D.G. (1972). Evaluation of an overlay technique for the recovery of Schistosoma mansoni cercariae. Bulletin of the World Health Organization. 47, pp. 125-7. 
Santini-Oliveira, M., Coler, R.N., Parra, J., Veloso, V., Jayashankar, L., Pinto, P.M. et al. (2016). Schistosomiasis vaccine candidate Sm14/GLA-SE: Phase 1 safety and immunogenicity clinical trial in healthy, male adults. Vaccine. 34, pp. 586-94.

Schets, F.M., Lodder, W.J. and De Roda Husman, A.M. (2010). Confirmation of the presence of Trichobilharzia by examination of water samples and snails following reports of cases of cercarial dermatitis. Parasitology. 137, pp. 77-83.

Schreiber, F.G. and Schubert, M. (1949). Experimental infection of the snail Australorbis glabratus with the trematode Schistosoma mansoni and the production of cercariae. Journal of Parasitology. 35, pp. 91-100.

Schwartz, D.A. (1981). Helminths in the induction of cancer II. Schistosoma haematobium and bladder cancer. Tropical and geographical medicine. 33, pp. 1-7.

Scrimgeour, E.M., Koul, R., Sallam, J. and Idris, M.A. (2001). Resurgence of schistosomiasis mansoni in Oman. Tropical Doctor. 31, pp. 185-6.

Shiff, C.J., Chandiwana, S.K., Graczyk, T., Chibatamoto, P. and Bradley, M. (1993). A trap for the detection of schistosome cercariae. Journal of Parasitology. 79, pp. 149-54.

Silva, R.R.E., Silva, J., Faerstein, N.F., Lenzi, H.L. and Rey, L. (1992). Natural infection of wild rodents by Schistosoma mansoni parasitological aspects. Memorias Do Instituto Oswaldo Cruz. 87, pp. 271-276.

Southgate, V.R., van Wijk, H.B. and Wright, C.A. (1976). Schistosomiasis at Loum, Cameroun; Schistosoma haematobium, S. intercalatum and their natural hybrid. Z Parasitenkd. 49, pp. 145-59.

Sow, S., Polman, K., Vereecken, K., Vercruysse, J., Gryseels, B. and de Vlas, S.J. (2008). The role of hygienic bathing after defecation in the transmission of Schistosoma mansoni. Transactions of the Royal Society of Tropical Medicine and Hygiene. 102, pp. 542-7.

Steinauer, M.L., Hanelt, B., Mwangi, I.N., Maina, G.M., Agola, L.E., Kinuthia, J.M. et al. (2008). Introgressive hybridization of human and rodent schistosome parasites in western Kenya. Molecular Ecology. 17, pp. 5062-74.

Théron, A. (1989). Hybrids between Schistosoma mansoni and S. rodhaini: characterization by cercarial emergence rhythms. Parasitology. 99 Pt 2, pp. 225-8.

Théron, A. (1979). A differential filtration technique for the measurement of schistosome cercarial densities in standing waters. Bulletin of the World Health Organization. 57, pp. 971-5.

Théron, A. and Combes, C. (1988). Genetic analysis of cercarial emergence rhythms of Schistosoma mansoni. Behavior Genetics. 18, pp. 201-209.

Théron, A. and Moné, H. (1984). Chronobiological aspects of the host-parasite relationships between Biomphalaria glabrata and Schistosoma mansoni: cercarial production and infectivity, and growth kinetics of the host. Journal of Invertebrate Pathology. 44, pp. 209-13.

Théron, A., Mouahid, G. and Moné, H. (1997). Schistosoma mansoni: cercarial shedding patterns from a mixed infection of Biomphalaria glabrata with two (early and late) chronobiological variants. Parasitology Research. 83, pp. 356-8.

Tran, M.H., Pearson, M.S., Bethony, J.M., Smyth, D.J., Jones, M.K., Duke, M. et al. (2006). Tetraspanins on the surface of Schistosoma mansoni are protective antigens against schistosomiasis. Nature Medicine. 12, pp. 835-40.

Turner, J.D., Narang, P., Coles, M.C. and Mountford, A.P. (2012). Blood flukes exploit Peyer's Patch lymphoid tissue to facilitate transmission from the mammalian host. PLoS Pathogens. 8, pp. e1003063.

Vos, T., Flaxman, A.D., Naghavi, M., Lozano, R., Michaud, C., Ezzati, M. et al. (2012). Years lived with disability (YLDs) for 1160 sequelae of 289 diseases and injuries 1990-2010: a systematic analysis for the Global Burden of Disease Study 2010. Lancet. 380, pp. 2163-96.

Wang, L.D., Chen, H.G., Guo, J.G., Zeng, X.J., Hong, X.L., Xiong, J.J. et al. (2009). A strategy to control transmission of 
Schistosoma japonicum in China. The New England Journal of Medicine. 360, pp. 121-8.

Wang, T.P., M. Johansen, V., Zhang, S.Q., Wang, F.F., Wu, W.D., Zhang, G.H. et al. (2005). Transmission of Schistosoma japonicum by humans and domestic animals in the Yangtze River valley, Anhui province, China. Acta Tropica. 96, pp. 198-204.

Watts, S. (2004). Women, water management and health. Emerging Infectious Diseases. 10, pp. 2025-6.

Webster, B.L., Diaw, O.T., Seye, M.M., Webster, J.P. and Rollinson, D. (2013). Introgressive hybridization of Schistosoma haematobium group species in Senegal: species barrier break down between ruminant and human schistosomes. PLOS Neglected Tropical Diseases. 7, pp. e2110.

Webster, B.L., Tchuenté, L.A.Tchuem, Jourdane, J. and Southgate, V.R. (2005). The interaction of Schistosoma haematobium and S. guineensis in Cameroon. Journal of Helminthology. 79, pp. 193-7.

Webster, J.P., Shrivastava, J., Johnson, P.J. and Blair, L. (2007). Is host-schistosome coevolution going anywhere?. BMC Evolutionary Biology. 7, pp. 91.

Whitfield, P.J., Bartlett, A., Khammo, N. and Clothier, R.H. (2003). Age-dependent survival and infectivity of Schistosoma mansoni cercariae. Parasitology. 127, pp. 29-35.

WHO (2017). fact sheet $N^{\circ} 115$ http://www.who.int/mediacentre/factsheets/fs115/en/.

WHO (2013). Schistosomiasis. Progress report 2001-2011 and strategic plan 2012-2020.

WHO (2012). Elimination of schistosomiasis. WHA65.21.

WHO (2006). Guidelines for the safe use of wastewater, excreta and greywater. Policy and Regulatory Aspects. 2, Wastewater use in agriculture, World Health Organization (WHO). Geneva, Switzerland.

WHO,. (2006). Preventive chemotherapy in human helminthiasis.

WHO (1989). Health guidelines for the use of wastewater in agriculture and aquaculture. Technical Report Series 778.

WHO,. and,. (2015). Join Monitoring Programme_25 years_Progress on sanitation and drinking water.

Wilson, R.A. (2009). The saga of schistosome migration and attrition. Parasitology. 136, pp. 1581-92.

Worrell, C., Xiao, N., Vidal, J.E., Chen, L., Zhong, B. and Remais, J. (2011). Field detection of Schistosoma japonicum cercariae in environmental water samples by quantitative PCR. Applied and Environmental Microbiology. 77, pp. 2192-5.

Wright, C.A., Southgate, V.R., van Wijk, H.B. and Moore, P.J. (1974). Hybrids between Schistosoma haematobium and S. intercalatum in Cameroon. Transactions of the Royal Society of Tropical Medicine and Hygiene. 68, pp. 413-4.

Xu, Y.Z. and Dresden, M.H. (1990). The hatching of schistosome eggs. Exp Parasitol. 70, pp. 236-40.

Yang, Y., Zhou, Y.B., Song, X.X., Li, S.Z., Zhong, B., Wang, T.P. et al. (2016). Integrated Control Strategy of Schistosomiasis in The People's Republic of China: Projects Involving Agriculture, Water Conservancy, Forestry, Sanitation and Environmental Modification. Adv Parasitol. 92, pp. 237-68.

Yoshino, T.P., Gourbal, B. and Théron, A. (2016). Schistosoma sporocysts. Schistosoma Biology, Pathology and Control. (Jamieson, B.G.M., ed.). Springer.

Zahed, N.Z., Ghandour, A.M., Banaja, A.A., Banerjee, R.K. and Dehlawi, M.S. (1996). Hamadryas baboons Papio hamadryas as maintenance hosts of Schistosoma mansoni in Saudi Arabia. Tropical Medicice and International Health. 1, pp. 449-55.

Zoni, A.C., Catala, L. and Ault, S.K. (2016). Schistosomiasis Prevalence and Intensity of Infection in Latin America and the 
Caribbean Countries, 1942-2014: A Systematic Review in the Context of a Regional Elimination Goal. PLOS Neglected Tropical Diseases. 10, pp. e0004493. 